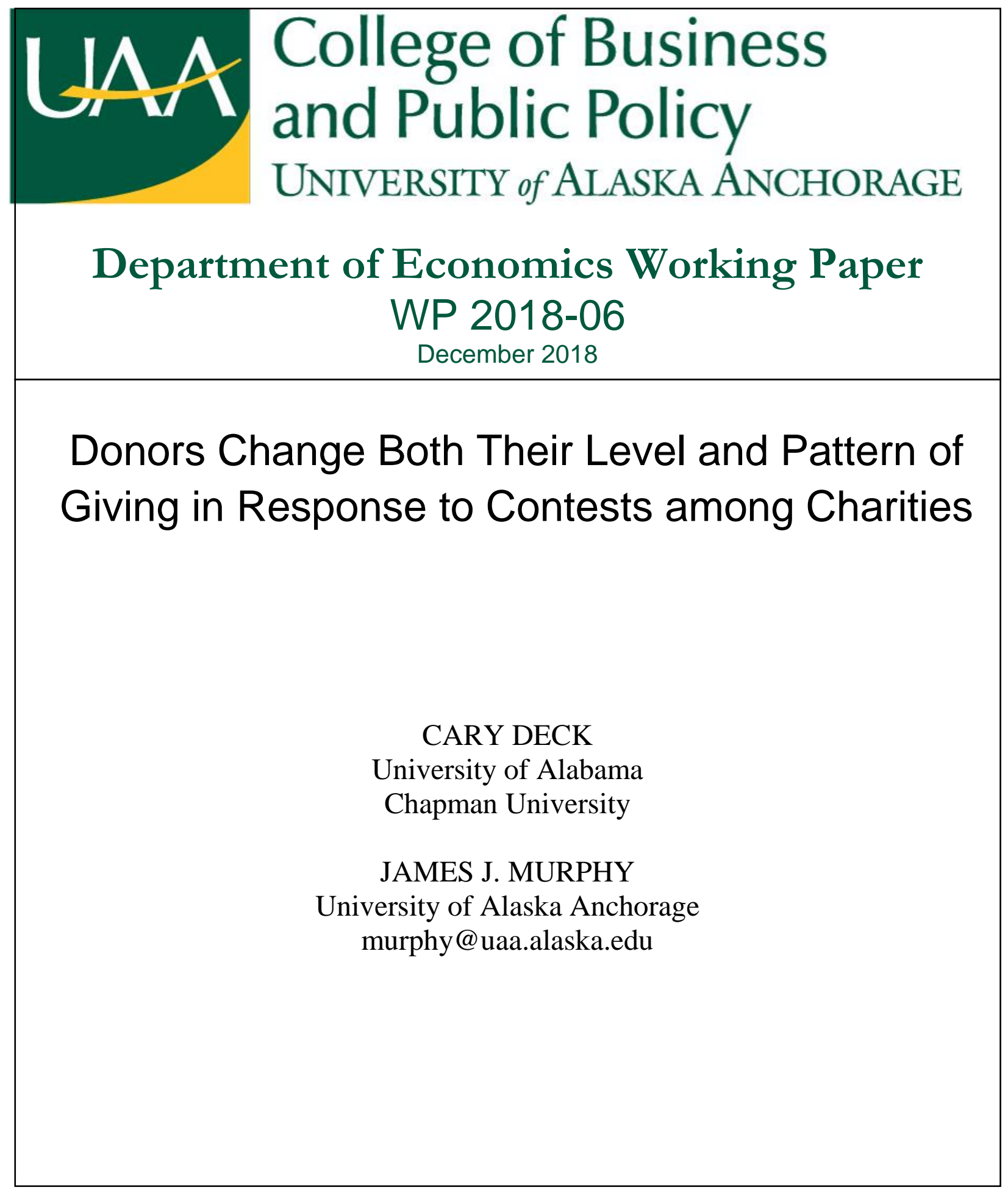

UAA DEPARTMENT OF ECONOMICS

3211 Providence Drive

Rasmuson Hall 302

Anchorage, AK 99508 


\section{Donors Change Both Their Level and Pattern of Giving in Response to Contests among Charities}

\author{
Cary Deck \\ University of Alabama \\ Chapman University
}

\author{
James J. Murphy* \\ Nankai University \\ University of Alaska Anchorage
}

December 2018

This paper examines two previously unexplored techniques for increasing charitable giving, both motivated by the contest literature. One is a fixed bonus that is paid to the organization receiving the most donations, akin to an all-pay auction. The other is a raffle-based bonus, akin to a Tullock contest. These two techniques are compared to a one-to-one matching program and a baseline condition in a within-subject laboratory experiment. The results reveal that all three bonus techniques lead to similar increases in donations to organizations eligible for the promotion. However, when only some organizations are eligible, the increases in giving to eligible organizations are primarily driven by a reallocation of donations away from ineligible organizations.

JEL Codes: C9, D6, D7

Key Words: Charitable Giving, Contests, All-pay Auction, Donation Matching, Laboratory Experiment Acknowledgements: The authors would like to thank Phil Grossman, Jonathan Meer, Roman Sheremeta, and Neslihan Uler as well as three anonymous reviewers for useful comments and suggestions. Funding was provided by the University of Alaska Anchorage College of Business and Public Policy.

* Please direct correspondence to murphy@uaa.alaska.edu. 


\section{Introduction}

From 2015 to 2017, ArkansasGives.Org hosted an annual 8 hour event in which charities operating in the state of Arkansas competed with each other for prizes of $\$ 5000, \$ 3000$, and $\$ 2000$ that were given to the organization in a particular category that came in first, second, and third, respectively in terms of donations received in the given timeframe. The categories included topical focuses such as animal welfare, economic development, the environment, health, and education. There were also prizes awarded by region of coverage and organization size with an organization competing along each dimension, and prizes based on the number of unique donors that contributed to the organization. In 2017 , over 900 organizations received combined donations of $\$ 5.6$ million dollars from over 23000 donors excluding the prizes. ${ }^{1}$

Alaska's Pick.Click.Give. program allows residents to donate a portion of their annual Permanent Fund Dividend to a nonprofit within the state. In 2017, Pick.Click.Give. offered prizes for the most money raised by a "new" nonprofit (i.e., one that did not participate the previous year), the greatest percentage increase in the number of donors, the greatest percentage increase in donation amount, and the greatest increase in the total number of donors. Prizes ranged between $\$ 1000$ and $\$ 5000$. Contests, such as the two described above, may simply cause donors to redirect their donations away from out-ofstate organizations, which are not eligible for the program.

From a donor's perspective, a contest that provides a bonus to the organization that raises the most money has similarities to an all-pay auction in that a slight increase in the amount donated could result in a discrete jump in the amount received by the organization. Borrowing from the contest literature, an alternative fundraising mechanism that, to the best of our knowledge has not been implemented in practice, is a variant of the Tullock contest. In this case, a charity's chance of receiving a lump sum amount is proportional to the amount of money raised by the charity relative to what other charities raise. In this sense the mechanism is like a raffle among charities. ${ }^{2}$ The extensive literature on contests indicates that people often bid aggressively (see Dechenaux 2015 for a survey), suggesting that these mechanisms may be highly effective at generating charitable giving. However, if donations to nonprofits participating in the contest are the result of a shift away from gifts to ineligible organizations, then the impact on overall charitable giving may be minimal.

In this paper, we use controlled laboratory experiments to evaluate the relative impact on donor behavior of these two types fundraising contests and the donation matching procedure that is standard in the literature and common in practice. We do not consider the effects that such mechanisms might have on the fundraising efforts of the recipient organizations. The laboratory provides an ideal testbed for evaluating new mechanisms because it affords increased control which allows us to identify the degree to which these procedures encourage new giving versus a reallocation of charitable giving among organizations, while not jeopardizing ongoing fundraising concerns as would be true with a field experiment. $^{3}$ Ultimately, we find that both a bonus to the charity that raises the most and a raffle

\footnotetext{
${ }^{1}$ The event was held April 6, 2017 and the results are available at https://www.arkansasgives.org/2017-results.

${ }^{2}$ This is distinct from a charity using a raffle as a fundraiser. When a charity holds a raffle, some proportion of the proceeds goes to the charity holding the raffle and some goes to the person with the winning raffle ticket. As described in more detail later in the paper, the raffle we are describing is one in which charities are the potential prize recipients. See Orzen (2008) for an analysis of using competition or contests in which it is donors who can receive the prize.

${ }^{3}$ As noted by Smith (1994), the laboratory provides a testing ground for new institutional designs.
} 
among charities generate substantially more giving for the organizations involved in these efforts. However, the increase in giving to bonus eligible organizations primarily comes at the expense of organizations that are not participating rather than through new giving. Further, donation patterns in these two mechanisms are indistinguishable from each or that observed with traditional matching.

\section{Background Literature}

Considerable attention has been given to methods to increase charitable giving. For example, List and Lucking-Reiley (2002) show that seed money leads to more donations and increases the likelihood of reaching a funding goal (see also Bracha et al 2011). A similar benefit is observed by Huck and Rasul (2011) when a lead gift can serve as a signal of quality. Work by Glazer and Konrad (1996), Li and Riyanto (2017) and Soetevent (2005) suggest people will give more when their decisions will be revealed. Shang and Croson (2009) report that providing donors with information about the gifts others have made so that social comparisons are possible increases donations. Frey and Meier (2004) and Croson and Shang (2008) draw similar conclusions, but Murphy et al. (2015) fail to replicate the result of Shang and Croson (2009).

Of all of the techniques that have been examined for increasing charitable giving, perhaps the most studied is a matching program in which each dollar given is matched by a third party (see Eckel and Grossman 2003, 2006a, 2006b, 2008, Davis et al. 2005, Davis and Millner 2005, and Davis 2006, Karlan and List 2007). Several of these papers compare matching to equivalent rebates. ${ }^{4}$ The behavioral pattern that emerges from these papers is that direct matching increases contributions and it is at least as effective in doing so as rebates. However, in a pair of field experiments Huck and Rasul (2011) and Huck et al. (2015) find that although linear matching schemes increase the total amount received by the charity, there is some crowding out of donations, and as a result the total amount donated decreases. Matching programs (and rebates) work by effectively reducing the price of giving. The importance of the price of giving is cleanly demonstrated in a dictator game experiment by Andreoni and Miller (2002). ${ }^{5}$ Recently, Charness and Holder (2016) look at matching in a competitive setting. Either individuals or small groups of people make donation decisions in which a match is only applied to the gifts of those who donate the most. They report that the group competition yielded the greatest amount of charitable giving. Because matching is a commonly used fundraising mechanism, it is a natural basis of comparison for evaluating other mechanisms, such as the ones we introduce.

The studies described above all focus on the decision to give to a single charity or nonprofit. ${ }^{6}$ In some cases, such as Eckel and Grossman (2003) the subjects can select which single nonprofit will receive their donations. Even in Charness and Holder (2016), in which the focus is on competition to earn the match, the recipient organizations are pre-assigned with one in-group (student oriented) and one out-group organization. However, in practice donors can support a wide array of organizations. Thus, an important question in this literature is the degree to which a promotion, such as a match or a prize,

\footnotetext{
${ }^{4} \mathrm{~A}$ program that matches a one dollar donation with an $\mathrm{m}$ dollar donation from a third party is mathematically equivalent to the third party offering a rebate of $\mathrm{m} /(\mathrm{m}+1)$ to the donor for each dollar given.

${ }^{5}$ Most laboratory experiments on charitable giving are essentially a dictator game decision in which the recipient is a charity.

${ }^{6}$ While most of the research in this area has focused on charities, in this paper we include organizations that some may not think of as charities (such as the National Rifle Association or Planned Parenthood) and thus we use the more general term nonprofit when referring to our work.
} 
leads to an increase in total giving and to what degree it leads to a reallocation of charitable giving. Reinstein (2011) finds empirical evidence in survey data that donations to one organization crowd out donations to others, but Scharf et al (2017) find that telethons and disaster appeals do not lead to drops in funding for other charities. In the laboratory, Reinstein (2012) reports that matching gifts to one charity can lead to reductions in donations to others. Filiz-Ozbay and Uler (2016) report a similar result for rebates: the increased donations associated with a higher rebate are partially offset by reduced giving to another charity. In a lab experiment motivated by the amyotrophic lateral sclerosis (ALS) ice bucket challenge, Harwell et al. (2015) find substantial crowding out from promotional campaigns that target a single charity. However, Meer (2017), using data from an online platform matching donors with recipients, concludes that a matching bonus does not crowd out giving to ineligible recipients, and Adena and Huck (2017) show that directing matches to alternative beneficiaries reduces crowding out. In the laboratory, we find that matching increases donations to bonus eligible organizations primarily at the expense of other potential recipients who are ineligible for the bonus.

Our research is also somewhat related to the literature on the use of contests and auctions as fundraising tools (e.g Dale 2004, Engers and McManus 2007, Carpenter et al. 2008, Schram and Onderstal 2009, Carpenter et al 2010, and Foster 2017). However, these papers focus on a distinctly different issue. Specifically, these papers investigate how personal characteristics like altruism or warm glow interact with private selfish motives to impact behavior in auctions and contests where at least some fraction of the revenue generated goes to charity but there are also personal returns. For example, a charity might auction off tickets to an event. If a bidder receives (warm glow) utility from charitable giving then she would place a higher bid for the tickets than if the seller was not a charity. Similarly, a person who is buying a raffle ticket where half the proceeds go to charity should purchase more tickets if they care about the total amount received by the charity than if half the proceeds went to a private party. By contrast, the contests that we study are among charitable organizations where an organization's ability to claim an additional contribution depends on its ability to fundraise as well as the fundraising success of other organizations.

\section{Experimental Procedure and Design}

The experiments were conducted in two discrete sets of sessions. The first were conducted in MarchNovember, 2016. We refer to these as the Original sessions, which are described below. After reviewing the results from these sessions, we conducted an additional set of experiments in September-October 2018. These new sessions are described after we present the results from the Original sessions.

\section{Procedures}

In the Original experiment, a total of 176 subjects participated in a one hour, four treatment, withinsubject study in the Vernon Smith Economic Science Laboratory at the University of Alaska Anchorage. The subjects were recruited from the lab's standing pool of volunteers, most of whom are undergraduate students.

In each of the 16 sessions, there were exactly 11 participants: a randomly chosen monitor and ten decision makers. At the beginning of a session, each subject randomly selected a slip of paper. One slip notified the participant that he or she would be the monitor. Each of the other ten people received a unique six character alpha-numeric code that was kept private and was used to maintain anonymity 
from the researcher, the monitor and the other subjects. As in Eckel and Grossman (2003), the monitor was paid \$10 to observe the experiment, assist with running it, and verify compliance with the protocol. After the monitor was selected and the other participants received their codes, the ten decision makers were seated at individual computer stations where they:

1. typed their unique code,

2. read the instructions (see appendix) and received information about eight nonprofit organizations,

3. made their decisions,

4. completed a brief survey (see appendix),

5. observed the outcome of their choices and the choices of the others,

6. received their payment, and

7. were dismissed from the experiment.

Subject payments adhered to the following double-blind protocol. ${ }^{7}$ All decision makers left the lab en masse and waited in the hall. One at a time, each person slid his or her code through a small slot in the door. The monitor collected the slip and verified that the researcher put the correct amount of cash in an unmarked envelope. The monitor then slid the envelope back through the slot in the door. This protocol ensured that neither the monitor nor the researcher was able to connect an individual to his or her decisions in the experiment or to know how much a particular individual received.

After the decision makers were dismissed, the monitor verified that the researcher sent the appropriate payment to each of the eight nonprofit organizations by observing that the correct amount of cash was placed in an envelope addressed to the nonprofit and accompanying the researcher to the university mail office. All donations were made anonymously.

\section{The Nonprofit Organizations}

Table 1 provides information about the eight nonprofit organizations used in this study. A printed version of this table was provided to the subjects, who could also see the same information if they clicked on the description button beside the organization's name on their computer. These organizations were selected based on a survey that was previously conducted in a class $(n=72)$. The survey listed 20 nonprofit organizations and asked respondents whether each organization was a "worthy cause and something you might be likely to donate to." There were five response options: extremely likely, somewhat likely, neither likely nor unlikely, somewhat unlikely, and extremely likely.

The decision to include an organization in the study was guided by a desire to maximize the chance that in the experiment there would be multiple organizations with which a participant was familiar and willing to support, and to have a combination of local, national, and international organizations represented. The organizations were also selected so that there were relationships between some organizations. For example, Planned Parenthood and American Family Association advocate opposing views with respect to abortion. In the class survey used to identify the nonprofit organizations to be included in the experiment, the correlation in opinions among survey respondents for these two

\footnotetext{
${ }^{7}$ In addition to the standard motivation to limit the impact of researcher observation, a double-blind protocol was used due to the potentially strong political or emotional feelings people may have towards some of the non-profit organizations (particularly those dealing with issues related to gun control and abortion).
} 
organizations was $\rho=-0.22$ ( $p$-value $=0.07$ ). An opposing relationship also exists between the National Rifle Association Foundation and the Brady Campaign to Prevent Gun Violence $(\rho=-0.12$, $p$-value $=$ 0.33). However, Bean's Cafe and Food Bank of Alaska have similar missions to help the homeless in the Anchorage area. Survey responses are consistent with these organizations being viewed as substitutes ( $\rho=0.65$, p-value $<0.01$ ). A high positive correlation also exists between Doctors Without Borders and the USA for the UNHCR $(\rho=0.54$, $p$-value $<0.01)$.

\section{The Decisions}

Each person was endowed with $\$ 10$, not including the $\$ 5$ they were promised during recruitment for showing up on time. Participants faced four allocation decisions (treatments). In each of the four decision tasks, the participants had to indicate how much to donate to each organization (in $\$ 0.25$ increments), and how much to "keep for yourself." The total allocation among the eight organizations plus the amount kept for oneself had to exactly equal $\$ 10$. This differs from most previous studies, such as Eckel and Grossman (2003), in that participants could donate to multiple organizations. As the participants knew in advance, one of the four allocation decisions was randomly selected for implementation at the end of the session. This random selection was done by the monitor rolling a four-sided die.

The four allocation decision tasks (treatments) were described in the instructions as follows:

Baseline: "You may donate any portion of your $\$ 10$ that you wish to one or more of the 8 nonprofit organizations listed on your screen."

Matching Bonus: "Four nonprofit organizations have been selected at random to be eligible for a matching bonus. Each quarter you donate to an eligible nonprofit organization will be matched so that the eligible organization receives twice the amount you donate. Everyone in the experiment has the same set of 4 eligible nonprofits."

Bonus to Top: "Four nonprofit organizations have been selected at random to be eligible for a top recipient bonus. An additional $\$ 100$ bonus donation will be made to the one nonprofit (of the four that are eligible) that receives the most money donated by you and the other 9 participants. In the case of a tie, the recipient of the bonus will be selected randomly. Everyone in the experiment has the same set of 4 eligible nonprofits." 8

Raffle Bonus: "Four nonprofit organizations have been selected at random to be eligible for a bonus raffle. A raffle will be held to select one nonprofit (of the four that are eligible) to receive a $\$ 100$ bonus donation. For each quarter anyone donates to an eligible nonprofit, that nonprofit will receive a raffle ticket. One raffle ticket will be randomly drawn and the eligible nonprofit that has the winning raffle ticket will receive the $\$ 100$ bonus. Everyone in the experiment has the same set of 4 eligible nonprofits." ${ }^{9}$

\footnotetext{
${ }^{8}$ In the event of a tie, one of the organizations receiving the largest total donations would have been randomly selected. This did not occur in the experiment.

${ }^{9}$ In the event that no eligible organization received a donation, the bonus would have been randomly allocated to one of the eligible organizations. This did not occur in the experiment.
} 
The $\$ 100$ bonus for the Bonus to Top and Raffle treatments was set to equalize the maximum amount that could be given to nonprofit organizations across the three bonus treatments since the Match treatment involved a one-to-one match for ten subjects with $\$ 10$ each. ${ }^{10}$

Within a session, the set of eligible and ineligible organizations was the same for everyone and for all treatments. Having multiple eligible and ineligible organizations is an important aspect of the design as it parallels the way such events work in the field. While matching campaigns are often focused on a single organization, multiple organizations may run such campaigns at the same time. The organizers of bonus campaigns would also need to specify the set of eligible organizations as a practical matter. For example, ArkansasGives.org, which operates a Bonus to Top contest is limited to charities operating in Arkansas meaning people who may also value organizations operating in other areas have to decide how to allocate money over eligible and ineligible charities. Additionally, because participants have their own preferences over organizations, having multiple organizations increases the chance there is some organization that a participant values in both groups. ${ }^{11}$ However, the four organizations that were bonus eligible were randomly determined for each session and thus differed across sessions. By informing subjects that eligible nonprofits were randomly selected, we avoid concerns about eligibility being a signal of the quality of the nonprofits, which has been shown to influence charity choice (Brown, et al. 2017). ${ }^{12}$ Each subject in a session experienced the four allocation choices in a random order. ${ }^{13}$ The order in which the organizations appeared on the screen was randomized across subjects, but was fixed for the four decisions that an individual faced. This randomization was constrained so that the four eligible organizations were grouped together, and this group of four eligible organizations was randomly assigned to appear first or second. Keep for self was always listed last. Figure 1 shows a sample screenshot. As shown in the figure, the bonus eligible organizations were clearly marked on the screen.

\section{Results}

This section presents the relative performance of the different treatments in terms of the donation amounts, and the number and type of organizations that received funding. We do not offer any hypotheses about point estimates or comparative statics because doing so would require a priori knowledge of individual preferences for the impact of his/her donation amount, the amount he/she cause the organization to receive, and the distribution of donations among the organizations, as well as the individual's beliefs about the preferences of the other subjects (and, of course, his/her higher order

\footnotetext{
${ }^{10}$ A priori, it was not possible to know how much would be donated under the matching procedure to equate the costs of the three programs. However, our design offers at least two advantages. First it follows the approach of Isaac and Walker (1988) in holding the socially optimal outcome constant across the bonus treatments. Second, it seems more plausible that a philanthropist would commit $\$ X$ to be used to promote charitable giving and then decide what type of promotion to use, which perhaps makes our setting somewhat more realistic.

${ }^{11}$ While it is possible to restrict the number of organizations down to two or three that the participant cares about, for the matching procedure because outcomes are based on individual decisions, this is not possible for the Bonus Raffle or Bonus to Top as outcomes under these procedure depend on the choices of others.

12 The notion that eligibility does not serve as a signal of quality is also enhanced by the use of a within subject design.

${ }^{13}$ Subjects knew there were four treatments, but did not know what subsequent treatments were nor could they revisit a previous decision.
} 
beliefs).${ }^{14}$ Instead, we focus on a comparison of the behavioral outcomes under different donation incentive mechanisms.

Table 2 presents summary statistics of donation decisions in all treatments. To provide a reference for evaluating the effects of the three bonus treatments, we begin with an overview of donation decisions in the Baseline Treatment. The average amount kept (out of \$10) by a subject in the Baseline was $\$ 4.48 .{ }^{15}$ To facilitate comparisons with the three Bonus treatments, in Table 2 the remaining $\$ 5.52$ that was donated to nonprofits in the Baseline is separated into the amounts given to the organizations that were eligible or ineligible in the other treatments. Since there was no bonus in the Baseline and eligibility status was not identified, the donation patterns should be the same regardless of "eligibility" in the Baseline and indeed this was the case. ${ }^{16}$ On average people gave to a total of 3.88 organizations and $12.5 \%$ did not donate to any organization. Figure 2 shows the distribution of the number of organizations to which people donated. Random effects Tobit regressions (see appendix, Table A1) suggest that there are no statistically significant differences among the bonus treatments (first row of hypothesis tests), but that each of the three bonus treatments increases the number of organizations to which subjects donate relative to the Baseline (see hypothesis tests comparing treatment to Baseline).

Figure 3 shows the average donation to each organization in the Baseline, separated based on whether the organization was eligible for a bonus in the other three treatments to facilitate comparisons. Figure 4 reports the percent of subjects (out of 160) who donated a positive amount to each organization in the Baseline Treatment. Interestingly, two of the three organizations receiving the most money were local nonprofits focused on the poor (Beans Café and the Food Bank of Alaska). This general pattern of nonprofit rankings was consistent across the other treatments as well.

We now turn to the aggregate effect of the bonuses. The unconditional mean total giving to all organizations by subjects in the Baseline was $\$ 5.52$. When half of the organizations were eligible for one of the bonus treatments, the unconditional mean total giving increased slightly: by $7 \%$ in the Bonus to Top Treatment (total giving averaged $\$ 5.88$ ), by $10 \%$ with a Bonus Raffle $(\$ 6.05)$, and by $7 \%$ with a Matching Bonus (\$5.92). ${ }^{17}$

More importantly, Table 2 also shows there is a substantial increase in donations to eligible organizations, which comes largely at the expense of the ineligible organizations. Donations to eligible organizations in each of the bonus treatments are about 2.5 times higher than the amount received by

\footnotetext{
${ }^{14}$ Preferences over the distribution of donations may arise, for example, when an individual donates to one organization to offset the donations of others to an opposing organization (e.g. how much someone wants to donate to the Brady Campaign may depend upon how much she expects the NRA will receive). In a similar vein, one might give to a less preferred eligible nonprofit to prevent an undesirable organization from winning the bonus. Data from our matching treatment, presented below, suggests that utility is not separable across nonprofits as other organizations being eligible for a match impacts giving to ineligible organizations.

15 This level of giving is higher than might be expected. While it is not unusual to see subjects give \$5 (out of \$10) to another person in a dictator game, that result is usually observed in a low social distance environment. However, the use of a double blind procedure typically leads to far more self-interested behavior (see, for example, Hoffman et al 1994).

${ }^{16}$ Recall that the set of four charities eligible for a bonus was fixed across the three bonus treatments for the 10 participants within a given session, but varied randomly between sessions.

${ }^{17}$ This small increase in total giving in the Matching Bonus treatment is inconsistent with the results reported in Huck and Rasul (2011) and Huck et al (2015).
} 
the ineligible organizations, which works out to approximately a $\$ 2.50$ difference between giving to eligible and ineligible organizations when there is a bonus.

To explore these patterns more formally, the first three models in Table 3 reports regression analysis of the impact of each promotion on total giving, giving to eligible organizations and giving to ineligible organizations. The last three models include additional controls for order effects and survey responses. Following Eckel and Grossman (2003), the Altruism variable is from the Self-Report Altruism Scale (Rushton et al., 1981). The model specification includes a random effect for each subject and clusters standard errors by session. ${ }^{18}$

Consistent with the discussion of summary statistics above, in both models 1 and 4 , the three bonus treatments yielded a small, but statistically significant, increase in total giving (about 6-10\%). In both models, a Wald $\chi^{2}$ test of the joint hypothesis that treatment effect is equal in the three bonus treatments cannot be rejected. This forms the basis for Finding 1:

Finding 1. Matching, Bonus-to-Top, and Bonus Raffle each have a small, but statistically significant, positive effect on total giving.

While Finding 1 indicates that there is only a small effect on total giving from the three promotions, this does not imply that the promotions do not impact giving. Figure 5 shows that the average contribution to each nonprofit when it is eligible for a promotion versus when it is not, and Figure 6 shows the percent of participants who donated to each nonprofit. These figures are based on donations in the three bonus treatments combined. It is clear that donations to a nonprofit are higher when it is eligible for a bonus than when it is not (Figure 5) and more people give to eligible organizations (Figure 6).

Statistically, Model 2 of Table 3 reveals that bonuses increase giving to organization that are eligible to receive the bonus. Specifically, eligibility for a bonus increases giving by about $45 \%$ relative to the Baseline. Model 5 yields a qualitatively similar conclusion. This pattern is consistent with previous experiments on matching and provides the basis for Finding 2.

Finding 2. Matching, Bonus-to-Top, and Bonus Raffle each increases giving to eligible recipients.

Findings 1 and 2 are consistent because giving to nonprofits drops precipitously when that organization is not eligible for bonuses, but other organizations are. Models 3 and 6 show a $65-70 \%$ decrease in giving to ineligible organizations. This provides the support for Finding 3.

Finding 3. Matching, Bonus-to-Top, and Bonus Raffle each decreases giving to ineligible recipients.

To this point, we have considered the Matching, Bonus-to-Top, and Bonus Raffle treatments as interchangeable. This is because the subjects appear to have largely done so as well. In all six models presented in Table 3, a Wald $\chi^{2}$ test of the joint hypothesis that treatment effect is equal for the three bonus treatments cannot be rejected at any conventional level of significance. This is the justification for Finding 4.

Finding 4. Matching, Bonus-to-Top, and Bonus Raffle have similar impacts on giving.

\footnotetext{
${ }^{18}$ While each subject makes decisions in isolation, the set of eligible organizations varies by session. Because one's choices may depend on beliefs about the donation patterns of others, these factors may be correlated since all of the subjects in a session are observing the same group of fellow participants. A random effects Tobit model yields the same qualitative conclusions.
} 
Finally, we briefly investigate how the different mechanisms impact the distribution of giving by individuals. For 71 of the subjects, a unique favorite organization can be identified as the organization to which the individual gave the most in Baseline. Table 4 reports how the amount donated to a favorite charity varied with bonus eligibility for each of the three mechanisms. Three interesting patterns emerge from this table. First, as one would expect people give more to their favorite organization when it is eligible for a bonus than when it is not. Second, the amount of given to a favorite organization, conditional on eligibility, is similar across all three bonuses. Third, although not surprising, it is worth also noting that donations to favorites decrease when a favorite is ineligible for a bonus. ${ }^{19}$ When the favorite is eligible, the mean donation in the Baseline is slightly higher than in the three Bonus treatments, but this difference is not statistically significant.

\section{Impact of Having Ineligible Organizations}

After observing the data presented in the previous section, a natural question to ask is the degree to which the impact of the bonuses was affected by the presence of ineligible organizations. After all, if every organization were eligible, then a donor could not divert funds from an ineligible to an eligible organization. To explore this issue, we conducted an additional experiment in which all eight organizations were eligible for the bonus. Otherwise, the design (random order of treatments, random arrangements of organizations, the identity of the organizations, the subject pool, etc.) was identical. ${ }^{20}$ A total of seven sessions, each with ten subjects (plus a monitor), was conducted. ${ }^{21}$ Subjects from the original experiment were not permitted to participate in this new experiment. We refer to this new experiment as the "All Organizations Bonus Eligible" sessions.

For simplicity, we repeated the analysis presented in the previous section using the new All Organizations Bonus Eligible data. Table 5 is comparable to Table 2. As shown in Table 5 , the average amount donated (out of $\$ 10$ ) by a subject in the Baseline was $\$ 5.11$. In the three bonus treatments the amount donated varied between $\$ 5.47$ and $\$ 5.89$. Thus, more money was donated in each of the three bonus treatments than in the Baseline in these data, similar to what we observed previously. Table 6 presents a regression analysis of the new All Organizations Bonus Eligible data, similar to that presented in Table 3 for the original data. The results in Table 3 indicate that only the Bonus Raffle and the Bonus to Top mechanisms generated statistically more giving than the Baseline; however, there is only at most weak evidence that the three bonus treatments perform differentially (see lower panel of Table 6, last row of hypothesis tests). Hence, it does not appear that the crowding in observed in our original experiment is due to the presence of ineligible organizations, although the success of matching in generating new giving may be affected by the presence of ineligible organizations. In the appendix Table A2, we report results from a regression analysis that directly compares donation amounts between the two sets of experiments. Those results indicate that Baseline giving is the same in the two

\footnotetext{
${ }^{19}$ All three observations are based on pairwise comparisons using t-tests, and are supported with $p$-values between 0.00 and 0.02 .

${ }^{20}$ Approximately 23 months passed between two sets of experiments. Thus, it is possible that some aspects of the student population from which the subjects were drawn may have changed. However, as discussed later, behavior in the Baseline treatments of the original experiment and the new experiment are similar, which suggests that the composition of the participants is not a major issue.

${ }^{21}$ While this is a smaller number of sessions than in the original experiment, here there is no selection of which organizations are bonus eligible which drove the need for a greater sample size in the original set of experiments.
} 
samples. Further, the total amount donated in each of the three bonus treatments are statistically similar between the two samples and so are the size of the differences in giving between treatments.

Attitudes towards specific organizations are shown in Figures 8 through 11, which are comparable to Figures 3-6 but with the All Organizations Bonus Eligible data. The patterns of giving to specific organizations shown in these figures are similar to those with the original data: amount given in the Baseline (Figure 3 versus Figure 8), percent donating in Baseline (Figure 4 versus Figure 9), average amount given when bonus eligible (Figure 5 versus Figure 10), and percent giving when bonus eligible (Figure 6 versus Figure 11). In both data sets, the most popular organizations were Bean's Café, Doctors without Borders, and Food Bank of Alaska. The least popular were American Family Association, the Brady Campaign to Prevent Gun Violence, and the National Rifle Association Foundation.

Table 5 also reports the average number of organizations to which subjects donated in the All Organizations Bonus Eligible sessions. In all four treatments, the average is between three and four organizations. As with the previous data, there is considerable heterogeneity in the number of organizations subjects support, see Figure 7. Tobit regressions, reported in Table A1, indicate that the number of organizations to which subjects donated did not vary across the three bonus treatments in either the original sessions or the new All Organizations Bonus Eligible sessions (see first two rows of hypothesis tests). The bonus treatments increase the number of organization to which subjects donate treatment relative to the Baseline, just as before. Further, Kolmogorov-Smirnov tests comparing the distribution of the number of organizations to which subjects donate fail to reject the null hypothesis of no difference for each of the four treatments. ${ }^{22}$ The Tobit regressions reported in Table A1 lead to a similar conclusions.

\section{Discussion}

In a controlled laboratory experiment, we find that promotions like a one-to-one match, a bonus paid to the nonprofit receiving the largest total donation, or a raffle-based bonus do lead to increased giving to the organizations that are eligible to receive those bonuses. However, the evidence is clear that this windfall is not mainly the result of increased donor giving, but instead comes primarily at the expense of declining gifts to nonprofits that are not eligible for said bonus. Crowding out of donations to ineligible nonprofits accounts for roughly two-thirds of the increased giving to bonus eligible nonprofits; the other third is from an increase in overall giving. The crowding out that occurs in giving means that organizations must compete with each other for funds. Those charities that do not engage in various promotions are likely to lose out to those who do. This result appears to conflict with the conclusions drawn by Meer (2017), but not those of Filiz-Ozbay and Uler (2016). One possible explanation is that while the nonprofits in our study span a variety of issues from hunger to abortion to gun rights and FilizOzbay and Uler (2016) examine giving to help the homeless and to help animals, the data in Meer (2017) focuses exclusively on education. Thus, it may be that the increased giving observed by Meer (2017) is crowding out donations to other unobserved causes. Although not the focus of this study, ArkansasGives, Alaska's Pick.Click.Give and other large scale events focusing on charitable giving in general may create an incentive for organizations to compete with each other for donations, for example through increased advertising or effort, thereby moderating or potentially even reducing the

\footnotetext{
22 The p-values for these tests are 0.54, 0.92, 0.63, and 0.79 for Baseline, Bonus Raffle, Bonus to Top, and Matching, respectively.
} 
net charitable income..$^{23}$ This is clearly an area for further research, but our results on donor behavior shed light on the potential importance of this question by revealing a willingness to substitute among possible recipients.

Our experiment was also designed as a sort of horse race among three fundraising promotions. While matching is a common practice that has been shown to increase giving, our bonus to the top fundraising organization and our bonus raffle procedures are not. The laboratory provides a low cost means of testing novel institutions. Given the large empirical literature showing that all-pay auctions and Tullock contests, upon which our two bonus procedures are based, often lead to substantial overbidding, we expected these two procedures to generate significant increases in giving even relative to matching. However, all three procedures yielded the same pattern of giving. From a pragmatic perspective, our results may suggest matching is the more efficient means of encouraging giving to an eligible organization because it generated a similar increase in giving but required less bonus money to be paid out. This is because the bonus was fixed up front for the two new mechanisms while the cost of the match depended on donor behavior.

A few caveats to this conclusion are warranted. First, our study only considered a match rate of one-toone and the bonuses were set so that the maximum amount that could be given to charity was the same across all three promotions we considered. It is possible that smaller bonuses for the two contests could yield similar increases in giving making those program more efficient as well. Second, this assessment may hinge on the number of participants as the expected cost of a matching program would likely increase in the number of potential donors whereas the bonus contests have fixed prize payments. Similarly, the number of potential donors likely impacts a donor's perception that their decision will be pivotal in determining which organizations receive bonuses. It is also possible that the eligible organizations being randomly selected (in the treatments in which only half of the organizations were bonus eligible) may have influenced behavior because it suggested that subjects should treat the organizations equivalently. In practice, it is possible that donors may view an organization being eligible for a bonus as a signal of its quality or deservingness. From the point of view of the entity implementing the scheme, the optimal procedure would depend on the entity's own knowledge of, and preferences over, organizations as well as the entity's beliefs about the views and preferences of potential donors. For example, generating a larger increase in funding for an organization deemed less effective or valued may not be preferable to generating a smaller funding increase for a more effective or valued organization. Alternatively, one or more lead gifts may be more effective and directing funds to specific organizations as it could be perceived as a stronger signal of quality. All of these issues are potentially important to understand promotions for encouraging charitable giving. We hope that this work spurs further ideas for alternative methods to encourage charitable giving. While the bonus raffle and bonus to top promotions did not have the large effects we anticipated based on the contest literature, there are numerous other variations to be explored.

\footnotetext{
${ }^{23}$ Another example of a general promotion of charitable giving is Giving Tuesday, which is a day of giving that is scheduled annually on the Tuesday after the US Thanksgiving holiday.
} 


\section{References}

Adena, M. and Huck, S. (2017). Mathcing donations without crowding out? Some Theoretical considerations, a field, and a lab experiment. Journal of Public Economics, 148, 32-42.

Andreoni, J. and Miller, J. (2002). Giving according to GARP: An experimental test of the consistency of preferences s for altruism. Econometrica, 70(2), 737-753.

Bracha, A., Menietti, M., and Vesterlund, L. (2001). Seeds to succeed?: Sequential giving to public projects. Journal of Public Economics, 95 (5-6), 416-427.

Brown, A., Meer, J. and Willias, J.F. (2017). Social distance and quality ratings in charity choice. Journal of Behavioral and Experimental Economics, 66, 9-15.

Carpenter, J., Holmes, J., and Matthews, P. (2008). Charity auctions: a field experiment. The Economic Journal, 118, 92-113.

Carpenter, J., Holmes, J., and Matthews, P. (2010). Charity auctions in the experimental lab, In Research In Experimental Economics 13, 201-249, Bingly: Emerald Group Publishing.

Charness, G. and Holder, P. (2016). Charity in the laboratory: Matching, competition, and group identity. Working paper, UC Santa Barbara.

Croson, R., and Shang, J. Y. (2008). The impact of downward social information on contribution decisions. Experimental Economics, 11(3), 221-233.

Dale, D. (2004). Charitable Lottery Structure and Fund Raising: Theory and Evidence. Experimental Economics, 7(3), 217-234.

Davis, D. D., Millner, E. L., \& Reilly, R. J. (2005). Subsidy schemes and charitable contributions: a closer look. Experimental Economics, 8(2), 85-106.

Davis, D. D., and Millner, E. L. (2005). Rebates, matches, and consumer behavior. Southern Economic Journal, 410-421.

Davis, D. D. (2006). Rebate subsidies, matching subsidies and isolation effects. Judgment and Decision Making, 1(1), 13.

Dechenaux, E., Kovenock, D., and Sheremeta, R. M. (2015). A survey of experimental research on contests, all-pay auctions and tournaments. Experimental economics, 18(4), 609-669.

Eckel, C. C., and Grossman, P. J. (2003). Rebate versus matching: does how we subsidize charitable contributions matter? Journal of Public Economics, 87(3), 681-701.

Eckel, C. C., and Grossman, P. J. (2006). Do donors care about subsidy type: An experimental study. In R. Mark Isaac and Douglas D. Davis, eds., Experiments Investigating Fundraising and Charitable Contributors. Research in Experimental Economics 11, 157-176. Elsevier.

Eckel, C. C., and Grossman, P. J., (2006) Subsidizing charitable giving with rebates or matching: Further laboratory evidence. Southern Economic Journal 72(4), 794-807.

Eckel, C. C., and Grossman, P. J. (2008). Subsidizing charitable contributions: A natural field experiment comparing matching and rebate subsidies." Experimental Economics 11(3): 234-252. September 2008. 
Engers, M. and McManus, B. (2007). Charity Auctions. International Economic Review, 48(3), 953-994. Filiz-Ozbay, E. and Uler, N. (2016). Demand for Giving to Multiple Charities: An Experimental Study. Working paper. http://dx.doi.org/10.2139/ssrn.2782143

Foster, J. (2017). The Effects of Loss Aversion and Sunk Cost Sensitivity in All-pay Auctions for Charity, Working Paper, University of Wisconsin - Oshkosh.

Frey, B. S., and Meier, S. (2004). Social comparisons and pro-social behavior: Testing" conditional cooperation" in a field experiment. The American Economic Review, 94(5), 1717-1722.

Glazer, A. and Konrad, K. (1996). A signaling explanation for charity. American Economic Review, 86(4), 1019-1028.

Harwell, H., Eckel, C., Meneses, D., Moceri, C., Rauckhorst, M. and Zindler, A. (2015). Did the Ice Bucket Challenge Drain the Philanthropic Reservoir?: Evidence from a Real-Donation Lab Experiment. Texas A\&M Working Paper.

Hoffman, E., McCabe, K. and Smith, V. (1994). Preferences, Property Rights, and Anonymity in Bargaining Games. Games and Economic Behavior, 7(3), 346-380.

Huck, S. and Rasul, I. (2011). Matched fundraising: Evidence from a natural field experiment. Journal of Public Economics, 95,351-362.

Huck, S., Rasul, I. and Shephard, A. (2015). Comparing Charitable Fundraising Schemes: Evidence from a Natural Field Experiment and a Structural Model. American Economic Journal: Public Policy, 7(2),326369.

Isaac, R. M., and Walker, J. (1988). Group Size Effects in Public Goods Provision: The Voluntary Contributions Mechanism. Quarterly Journal of Economics, 103(1),179-199.

Nickerson, M., and List, J. A. (2007). Does price matter in charitable giving? Evidence from a large-scale natural field experiment. The American Economic Review, 97(5), 1774-1793.

Li, J. and Riyanto, Y. (2009). Category Reporting in Charitable Giving: An Experimental Analysis. Economic Inquiry, 55(1), 397-408.

List, J. A., and Lucking-Reiley, D. (2002). The effects of seed money and refunds on charitable giving: Experimental evidence from a university capital campaign. Journal of Political Economy, 110(1), 215-233.

Meer, J. (2017). Does fundraising create new giving? Journal of Public Economics, 145, 82-93.

Murphy, J. J., Batmunkh, N., Nilsson, B., and Ray, S. (2015). The impact of social information on the voluntary provision of public goods: A replication study. In Replication in experimental economics (pp. 41-50). Emerald Group Publishing Limited.

Orzen, H. (2008). Fundraising through competition: evidence from the lab. CeDEx Discussion Paper 2009-11, The University of Nottingham.

Reinstein, D. A. (2011). Does one charitable contribution come at the expense of another? The BE Journal of Economic Analysis \& Policy, 11(1), 1-54. 
Reinstein D. A. (2012). Substitution among charitable contributions: An experimental study. Working paper, University of Essex.

Rushton, J. P., Chrisjohn, R. D., and Fekken, G. C. (1981). The altruistic personality and the self-report altruism scale. Personality and Individual Differences, 2(4), 293-302.

Scharf, K., Ottoni-Wilhelm, M. and Smith, S. (2017). Lift and Shift: The Effect of Fundraising Interventions in Charity Space and Time, CEPR Discussion Paper 12338.

Schram, A. and Onderstal, S. (2009). Bidding to give: an experimental comparison of auctions for charity. International Economic Review, 50(2), 431-457.

Shang, J., and Croson, R. (2009). A field experiment in charitable contribution: The impact of social information on the voluntary provision of public goods. The Economic Journal, 119(540), 1422-1439.

Smith, V. L. (1994). Economics in the Laboratory. The Journal of Economic Perspectives, 8(1), 113-131.

Soetevent, A. R. (2005). Anonymity in giving in a natural context-a field experiment in 30 churches. Journal of Public Economics, 89(11), 2301-2323. 


\section{Table 1. Nonprofit Organizations and Descriptions Provided to Participants}

American Family Association (AFA): AFA is a large pro-family organization. Its mission is to inform, equip, and activate individuals to strengthen the moral foundations of American culture, and give aid to the church here and abroad in its task of fulfilling the Great Commission. They publish a monthly magazine, and they own and operate nearly 200 radio stations across the country under the American Family Radio (AFR) banner. AFA maintains activist web sites that rally Christian activists to contact companies asking them to drop their advertising from objectionable TV shows.

Bean's Café: Bean's Café maintains a center in Anchorage where the hungry and homeless are provided with hot nutritious meals, a warm and safe day shelter, information and referral assistance to health and human service programs. They target the poorest people in Anchorage, the street people, the homeless, the chronically mentally ill, and the needy elderly.

Brady Campaign to Prevent Gun Violence: As a large national, non-partisan, grassroots organization leading the fight to prevent gun violence, the Brady Campaign is dedicated to creating an America free from gun violence, where all Americans are safe at home, at school, at work, and in their communities. They work to reform the gun industry and educate the public about gun violence through litigation and grassroots mobilization, and work to enact and enforce sensible regulations to reduce gun violence including regulations governing the gun industry.

Doctors Without Borders: Doctors Without Borders is an international medical humanitarian organization that provides aid in nearly 60 countries to people whose survival is threatened by violence, neglect, or catastrophe, primarily due to armed conflict, epidemics, malnutrition, exclusion from health care, or natural disasters.

Food Bank of Alaska: Food Bank of Alaska is dedicated to eliminating hunger in Alaska by obtaining and providing food to 300 partner food pantries and meal programs statewide as well as through anti-hunger leadership. They believe no one deserves to be hungry.

National Rifle Association Foundation: The NRA Foundation raises contributions in support of a wide range of firearm related public interest activities of the National Rifle Association of America and other organizations that defend and foster the Second Amendment rights of all law-abiding Americans. These activities are designed to promote firearms and hunting safety, to enhance marksmanship skills of those participating in the shooting sports, and to educate the general public about firearms in their historic, technological and artistic context.

Planned Parenthood Federation of America: Planned Parenthood is a provider of reproductive health care. Planned Parenthood has promoted women's health and well-being, based on respect for each individual's right to make informed, independent decisions about health, sex, and family planning. PPFA works to provide trusted community healthcare; inform and educated the community; lead the reproductive health and rights movement; and advance global health.

USA for the United Nations High Commissioner for Refugees (UNHCR): USA for UNHCR is an independent organization that provides support for the humanitarian work of the United Nations High Commissioner for Refugees through fundraising and education. The organization supports refugee protection and relief programs around the world, meeting needs by providing resources to the world's most vulnerable people. They support UNHCR's operations around the world to protect refugees, internally displaced people, and former refugees who are returning home. 
Table 2. Summary Statistics (Original Sessions)

\begin{tabular}{|c|c|c|c|c|c|}
\hline & & & tment & & \\
\hline & $\begin{array}{c}\text { T0. } \\
\text { Baseline }\end{array}$ & $\begin{array}{l}\text { T1. Bonus } \\
\text { Raffle }\end{array}$ & $\begin{array}{l}\text { T2. Bonus to } \\
\text { Top Org. }\end{array}$ & $\begin{array}{c}\text { T3. } \\
\text { Matching } \\
\text { Bonus }\end{array}$ & $\begin{array}{c}\text { All } \\
\text { treatment } \\
\text { combined }\end{array}$ \\
\hline Unconditional Mean Amo & nated $^{a}$ & & & & \\
\hline Eligible Orgs. & 2.94 & 4.27 & 4.23 & 4.24 & \\
\hline & $(2.43)$ & (2.90) & (3.06) & (2.98) & \\
\hline Ineligible Orgs. & 2.58 & 1.77 & 1.64 & 1.67 & \\
\hline & $(2.25)$ & (1.93) & (1.97) & $(1.80)$ & \\
\hline Total (Eligible + Ineligible & 5.52 & 6.05 & 5.88 & 5.92 & \\
\hline Orgs.) & (3.51) & (3.38) & $(3.46)$ & $(3.40)$ & \\
\hline Conditional Mean Amoun & ted $^{a}$ & & & & \\
\hline Eligible Orgs. & 3.70 & 4.65 & 4.67 & 4.62 & \\
\hline & $(2.15)$ & $(2.72)$ & $(2.88)$ & $(2.81)$ & \\
\hline Ineligible Orgs. & 3.35 & 2.84 & 2.96 & 2.63 & \\
\hline & (1.99) & $(1.72)$ & (1.77) & (1.61) & \\
\hline Total (Eligible + Ineligible & 6.30 & 6.45 & 6.39 & 6.27 & \\
\hline Orgs.) & (3.01) & (3.10) & (3.12) & (3.17) & \\
\hline Number of Subjects & & & & & \\
\hline Donation Amount $=0$ & $20 / 160$ & $10 / 160$ & $13 / 160$ & $9 / 160$ & $6 / 160$ \\
\hline & $(12.5 \%)$ & $(6.3 \%)$ & $(8.1 \%)$ & $(5.6 \%)$ & $(3.8 \%)$ \\
\hline Donation Amount $=10$ & $25 / 160$ & $33 / 160$ & $33 / 160$ & $33 / 160$ & $20 / 160$ \\
\hline & $(15.6 \%)$ & $(20.6 \%)$ & $(20.6 \%)$ & $(20.6 \%)$ & $(12.5 \%)$ \\
\hline Donation Amount $>0$ & $140 / 160$ & $150 / 160$ & $147 / 160$ & $151 / 160$ & $137 / 160$ \\
\hline & $(87.5 \%)$ & (93.8\%) & (91.9\%) & $(94.4 \%)$ & $(85.6 \%)$ \\
\hline
\end{tabular}

Mean Number of Orgs. Receiving Donation ${ }^{a}$

\begin{tabular}{lccccc}
\hline Eligible Orgs. & 2.04 & & 2.45 & 2.17 & 2.42 \\
& $(1.40)$ & & $1.32)$ & $(1.34)$ & $(1.26)$ \\
Ineligible Orgs. & 1.83 & 1.58 & 1.44 & 1.52 \\
& $(1.42)$ & $(1.54)$ & $(1.56)$ & $(1.49)$ \\
Total (Eligible + Ineligible & 3.88 & 4.03 & 3.61 & 3.94 \\
Orgs.) & $(2.58)$ & $(2.50)$ & $(2.59)$ & $(2.40)$
\end{tabular}

${ }^{\text {a }}$ Standard deviation in parenthesis. 
Table 3. Regression Analysis of Treatment Effects on Amount Donated by an Individual (Original Sessions)

\begin{tabular}{|c|c|c|c|c|c|c|}
\hline VARIABLES & $\begin{array}{l}(1) \\
\text { total }\end{array}$ & $\begin{array}{c}\text { (2) } \\
\text { eligible }\end{array}$ & $\begin{array}{c}\text { (3) } \\
\text { ineligible }\end{array}$ & $\begin{array}{l}\text { (4) } \\
\text { total }\end{array}$ & $\begin{array}{c}\text { (5) } \\
\text { eligible }\end{array}$ & $\begin{array}{c}(6) \\
\text { ineligible }\end{array}$ \\
\hline Treatment: Bonus Raffle & $\begin{array}{c}0.53^{* * *} \\
(4.52)\end{array}$ & $\begin{array}{c}1.33^{* * *} \\
(5.92)\end{array}$ & $\begin{array}{c}-0.80 * * * \\
(-4.61)\end{array}$ & $\begin{array}{c}0.52^{* * *} \\
(4.48)\end{array}$ & $\begin{array}{c}1.35^{* * *} \\
(6.14)\end{array}$ & $\begin{array}{c}-0.83^{* * *} \\
(-4.59)\end{array}$ \\
\hline Treatment: Bonus to Top & $\begin{array}{c}0.36^{* * *} \\
(3.06)\end{array}$ & $\begin{array}{c}1.29 * * * \\
(5.78)\end{array}$ & $\begin{array}{c}-0.93^{* * *} \\
(-5.47)\end{array}$ & $\begin{array}{c}0.36^{* * *} \\
(2.96)\end{array}$ & $\begin{array}{c}1.28 * * * \\
(6.13)\end{array}$ & $\begin{array}{c}-0.93 * * * \\
(-5.67)\end{array}$ \\
\hline Treatment: Matching Bonus & $\begin{array}{l}0.40 * * \\
(2.37)\end{array}$ & $\begin{array}{c}1.30^{* * *} \\
(6.80)\end{array}$ & $\begin{array}{c}-0.90 * * * \\
(-6.75)\end{array}$ & $\begin{array}{c}0.39 * * \\
(2.39)\end{array}$ & $\begin{array}{c}1.33^{* * *} \\
(7.14)\end{array}$ & $\begin{array}{c}-0.94 * * * \\
(-6.85)\end{array}$ \\
\hline Sequence $=2$ & & & & $\begin{array}{l}-0.12 \\
(-0.65)\end{array}$ & $\begin{array}{c}0.26 \\
(1.15)\end{array}$ & $\begin{array}{l}-0.37^{* *} \\
(-2.28)\end{array}$ \\
\hline Sequence $=3$ & & & & $\begin{array}{c}-0.13 \\
(-0.60)\end{array}$ & $\begin{array}{c}0.28 \\
(1.14)\end{array}$ & $\begin{array}{c}-0.42^{* * *} \\
(-2.63)\end{array}$ \\
\hline Sequence $=4$ & & & & $\begin{array}{c}-0.05 \\
(-0.25)\end{array}$ & $\begin{array}{c}0.26 \\
(1.27)\end{array}$ & $\begin{array}{l}-0.31^{*} \\
(-1.96)\end{array}$ \\
\hline Male & & & & $\begin{array}{c}-0.74 \\
(-1.21)\end{array}$ & $\begin{array}{l}-0.41 \\
(-0.99)\end{array}$ & $\begin{array}{c}-0.33 \\
(-1.18)\end{array}$ \\
\hline Altruism & & & & $\begin{array}{c}0.05 * * * \\
(2.60)\end{array}$ & $\begin{array}{l}0.03^{*} \\
(1.72)\end{array}$ & $\begin{array}{c}0.02 * * * \\
(3.33)\end{array}$ \\
\hline Economics Major & & & & $\begin{array}{c}-1.12 \\
(-1.24)\end{array}$ & $\begin{array}{c}-0.68 \\
(-0.87)\end{array}$ & $\begin{array}{c}-0.44 \\
(-1.51)\end{array}$ \\
\hline Took at least 2 economics classes & & & & $\begin{array}{c}-1.39 * * \\
(-2.40)\end{array}$ & $\begin{array}{r}-1.00 * * \\
(-2.41)\end{array}$ & $\begin{array}{c}-0.39 \\
(-1.28)\end{array}$ \\
\hline Race $=$ White & & & & $\begin{array}{c}0.17 \\
(0.21)\end{array}$ & $\begin{array}{c}0.44 \\
(0.86)\end{array}$ & $\begin{array}{c}-0.28 \\
(-0.87)\end{array}$ \\
\hline Race=Asian & & & & $\begin{array}{c}0.14 \\
(0.17)\end{array}$ & $\begin{array}{c}0.15 \\
(0.29)\end{array}$ & $\begin{array}{l}-0.02 \\
(-0.05)\end{array}$ \\
\hline Under 25 years of Age & & & & $\begin{array}{c}0.11 \\
(0.19)\end{array}$ & $\begin{array}{c}-0.01 \\
(-0.02)\end{array}$ & $\begin{array}{c}0.12 \\
(0.49)\end{array}$ \\
\hline Constant & $\begin{array}{c}5.52^{* * *} \\
(17.10) \\
\end{array}$ & $\begin{array}{l}2.94 * * * \\
(13.76)\end{array}$ & $\begin{array}{c}2.58^{* * *} \\
(11.94) \\
\end{array}$ & $\begin{array}{c}4.72^{* * *} \\
(3.70) \\
\end{array}$ & $\begin{array}{l}2.13^{* *} \\
(2.05)\end{array}$ & $\begin{array}{c}2.59 * * * \\
(5.86) \\
\end{array}$ \\
\hline Observations & 640 & 640 & 640 & 640 & 640 & 640 \\
\hline Hypothesis Tests (p-values for treatm & nt effects) & 160 & 160 & 160 & 160 & 160 \\
\hline $\mathrm{H}_{0}:$ Baseline $=$ Bonus Raffle & $0.00 * * *$ & $0.00 * * *$ & $0.00 * * *$ & $0.00 * * *$ & $0.00 * * *$ & $0.00 * * *$ \\
\hline Ho: Baseline = Bonus to Top Org & $0.05 * *$ & $0.00 * * *$ & $0.00 * * *$ & $0.04 * *$ & $0.00 * * *$ & $0.00 * * *$ \\
\hline $\mathrm{H}_{0}:$ Baseline = Matching Bonus & $0.04 * *$ & $0.00 * * *$ & $0.00 * * *$ & $0.04 * *$ & $0.00 * * *$ & $0.00 * * *$ \\
\hline $\mathrm{H}_{0}$ : Bonus Raffle $=$ Bonus to Top Org. & 0.17 & 0.81 & 0.26 & 0.20 & 0.70 & 0.40 \\
\hline Ho: Bonus Raffle = Matching Bonus & 0.42 & 0.88 & 0.34 & 0.43 & 0.94 & 0.30 \\
\hline $\mathrm{H}_{0}$ : Bonus to Top Org. = Matching Bonus & 0.81 & 0.96 & 0.78 & 0.84 & 0.80 & 0.89 \\
\hline $\begin{array}{l}\text { Ho: Bonus Raffle = Bonus to Top Org. = } \\
\text { Matching Bonus }\end{array}$ & 0.35 & 0.97 & 0.49 & 0.41 & 0.92 & 0.55 \\
\hline
\end{tabular}


Table 4. Average Individual Donation to Favorite Organization (Original Sessions)

Average Donation when Average Donation when

Favorite is Eligible Favorite is Ineligible

Baseline

$\$ 3.21$

$\$ 2.52$

$\$ 3.16$

Bonus Raffle

$\$ 2.74$

$\$ 1.15$

Bonus to Top

$\$ 2.87$

$\$ 1.24$

Matching Bonus

$\$ 1.29$

Uses only the data from the 71 subjects with a unique favorite organization in the Baseline treatment. 
Table 5. Summary Statistics (All Organizations Bonus Eligible Sessions)

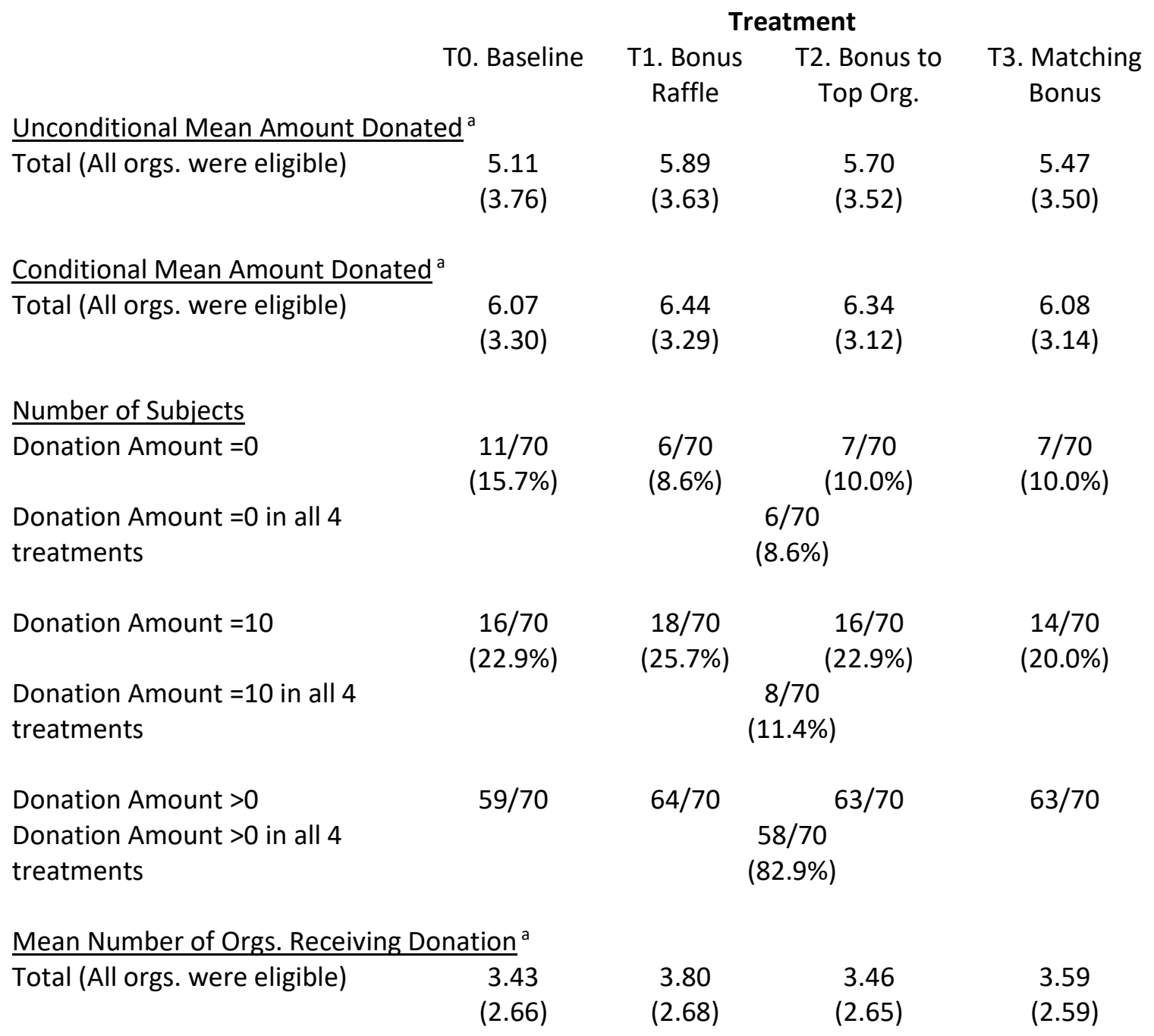

${ }^{\text {a }}$ Standard deviation in parenthesis. 
Table 6. Regression Analysis of Treatment Effects on Amount Donated by an Individual (All Organizations Bonus Eligible Sessions)

\begin{tabular}{|c|c|c|}
\hline & $\begin{array}{c}(1) \\
\text { Total }^{\mathrm{a}}\end{array}$ & $\begin{array}{c}(2) \\
\text { Total }^{a}\end{array}$ \\
\hline \multirow[t]{2}{*}{ T1. Bonus Raffle } & $0.78 * * *$ & $0.76 * * *$ \\
\hline & $(0.27)$ & $(0.26)$ \\
\hline \multirow[t]{2}{*}{ T2. Bonus to Top Org. } & $0.59 * *$ & $0.55^{* *}$ \\
\hline & $(0.28)$ & $(0.28)$ \\
\hline \multirow[t]{2}{*}{ T3. Matching Bonus } & 0.36 & 0.36 \\
\hline & $(0.29)$ & $(0.30)$ \\
\hline \multirow[t]{2}{*}{ Sequence $=2$} & & -0.12 \\
\hline & & $(0.25)$ \\
\hline \multirow[t]{2}{*}{ Sequence $=3$} & & -0.15 \\
\hline & & $(0.25)$ \\
\hline \multirow[t]{2}{*}{ Sequence $=4$} & & 0.20 \\
\hline & & (0.19) \\
\hline \multirow[t]{2}{*}{ Male } & & -0.26 \\
\hline & & $(0.86)$ \\
\hline \multirow[t]{2}{*}{ Altruism } & & -0.01 \\
\hline & & $(0.04)$ \\
\hline \multirow[t]{2}{*}{ Economics Major } & & -0.46 \\
\hline & & $(1.53)$ \\
\hline \multirow[t]{2}{*}{ Took at least 2 economics classes } & & 0.65 \\
\hline & & $(0.86)$ \\
\hline \multirow[t]{2}{*}{ Race $=$ White } & & 0.05 \\
\hline & & $(1.12)$ \\
\hline \multirow[t]{2}{*}{ Race=Asian } & & 0.88 \\
\hline & & $(1.11)$ \\
\hline \multirow[t]{2}{*}{ Under 25 years of Age } & & 0.60 \\
\hline & & $(1.08)$ \\
\hline \multirow[t]{2}{*}{ Constant } & $5.11 * * *$ & $4.91 * *$ \\
\hline & $(0.45)$ & $(2.04)$ \\
\hline \# Observations & 280 & 280 \\
\hline \# Unique Subjects & 70 & 70 \\
\hline \multicolumn{3}{|l|}{ Hypothesis Tests ( $p$-values for treatment effects) } \\
\hline $\mathrm{H}_{0}:$ Baseline $=$ Bonus Raffle & $0.00 * * *$ & $0.00 * * *$ \\
\hline $\mathrm{H}_{0}:$ Baseline $=$ Bonus to Top Org & $0.03 * *$ & $0.05 * *$ \\
\hline $\mathrm{H}_{0}:$ Baseline $=$ Matching Bonus & 0.22 & 0.23 \\
\hline $\mathrm{H}_{0}$ : Bonus Raffle $=$ Bonus to Top Org. & 0.38 & 0.33 \\
\hline $\mathrm{H}_{0}:$ Bonus Raffle $=$ Matching Bonus & $0.03 * *$ & $0.05 * *$ \\
\hline $\mathrm{H}_{0}:$ Bonus to Top Org. $=$ Matching Bonus & 0.20 & 0.27 \\
\hline $\mathrm{H}_{0}$ : Bonus Raffle $=$ Bonus to Top Org. = Matching Bonus & $0.09 *$ & 0.14 \\
\hline
\end{tabular}

${ }^{a}$ Note that since all nonprofits were eligible, total donations are identical to donations to eligible organizations. Results are based linear regression with random effects for each subject and standard errors clustered at the session level. Standard errors in parentheses. ${ }^{* * *} p<0.01,{ }^{* *} p<0.05,{ }^{*} p<0.10$ 
Table A1. Tobit Regression Analysis of Number of Organizations to which an Individual Donated (Original and All Organizations Bonus Eligible sessions combined)

\begin{tabular}{|c|c|c|}
\hline & $\begin{array}{c}\text { (1) } \\
\text { Number of } \\
\text { Organizations }\end{array}$ & $\begin{array}{c}\text { (2) } \\
\text { Number of } \\
\text { Organizations }\end{array}$ \\
\hline \multirow[t]{2}{*}{ All Organizations Bonus Eligible Sessions } & -1.05 & $-1.31^{*}$ \\
\hline & $(0.81)$ & $(0.79)$ \\
\hline \multirow[t]{2}{*}{ T1. Bonus Raffle } & $0.79 * * *$ & $0.73 * * *$ \\
\hline & $(0.26)$ & $(0.26)$ \\
\hline \multirow[t]{2}{*}{ T2. Bonus to Top Org. } & $0.49 *$ & $0.46^{*}$ \\
\hline & $(0.26)$ & $(0.26)$ \\
\hline \multirow[t]{2}{*}{ T3. Matching Bonus } & $0.61 * *$ & $0.58 * *$ \\
\hline & $(0.26)$ & $(0.26)$ \\
\hline \multirow{2}{*}{$\begin{array}{l}\text { All Organizations Bonus Eligible Sessions } \\
\text { x Bonus Raffle }\end{array}$} & 0.53 & 0.55 \\
\hline & $(0.47)$ & $(0.47)$ \\
\hline \multirow{2}{*}{$\begin{array}{l}\text { All Organizations Bonus Eligible Sessions } \\
\text { x Bonus to Top Org }\end{array}$} & 0.58 & 0.59 \\
\hline & $(0.47)$ & $(0.47)$ \\
\hline \multirow{2}{*}{$\begin{array}{l}\text { All Organizations Bonus Eligible Sessions } \\
\text { x Matching Bonus }\end{array}$} & 0.06 & 0.11 \\
\hline & $(0.47)$ & $(0.46)$ \\
\hline \multirow[t]{2}{*}{ Sequence $=2$} & & -0.24 \\
\hline & & $(0.22)$ \\
\hline \multirow[t]{2}{*}{ Sequence $=3$} & & -0.34 \\
\hline & & $(0.22)$ \\
\hline \multirow[t]{2}{*}{ Sequence=4 } & & 0.04 \\
\hline & & $(0.22)$ \\
\hline \multirow[t]{2}{*}{ Male } & & -0.79 \\
\hline & & $(0.71)$ \\
\hline \multirow[t]{2}{*}{ Altruism } & & $0.06 * *$ \\
\hline & & $(0.03)$ \\
\hline \multirow[t]{2}{*}{ Economics Major } & & -1.27 \\
\hline & & $(1.27)$ \\
\hline \multirow[t]{2}{*}{ Took at least 2 economics classes } & & $-1.40 *$ \\
\hline & & $(0.72)$ \\
\hline \multirow[t]{2}{*}{ Race=White } & & 0.44 \\
\hline & & $(0.87)$ \\
\hline \multirow[t]{2}{*}{ Race=Asian } & & 0.88 \\
\hline & & (1.04) \\
\hline \multirow[t]{2}{*}{ Under 25 years of Age } & & 0.16 \\
\hline & & $(0.79)$ \\
\hline \multirow[t]{2}{*}{ Constant } & $6.24 * * *$ & $4.92 * * *$ \\
\hline & $(0.46)$ & $(1.61)$ \\
\hline \# Observations & 920 & 920 \\
\hline \# Unique Subjects & 230 & 230 \\
\hline \multicolumn{3}{|c|}{ Hypothesis tests ( $\mathrm{p}$-values for $\mathrm{H}_{0}$ : Number of Organizations Equal for All Three Bonus Treatments) } \\
\hline Original Sessions & 0.53 & 0.59 \\
\hline All Organizations Bonus Eligible Sessions & 0.48 & 0.53 \\
\hline \multicolumn{3}{|l|}{ Hypothesis tests ( $\mathrm{p}$-values for $\mathrm{H}_{0}$ : Treatment = Baseline) } \\
\hline T1. Bonus Raffle (Original Sessions) & $0.00 * * *$ & $0.00 * * *$ \\
\hline T2. Bonus to Top (Original Sessions) & $0.06 *$ & $0.08 *$ \\
\hline T3. Matching Bonus (Original Sessions) & $0.02 * *$ & $0.03 * *$ \\
\hline T1. Bonus Raffle (All Organizations Bonus Eligible Sessions) & $0.00 * * *$ & $0.00 * * *$ \\
\hline T2. Bonus to Top (All Organizations Bonus Eligible Sessions) & $0.01 * * *$ & $0.01 * * *$ \\
\hline T3. Matching Bonus (All Organizations Bonus Eligible Sessions) & $0.08 *$ & $0.07 *$ \\
\hline
\end{tabular}


Hypothesis tests (p-values for $\mathrm{H}_{0}$ : Original Sessions = All Organizations Bonus Eligible Sessions)

Within Treatment Comparisons

T0. Baseline

0.198

$0.098 *$

T1. Bonus Raffle

0.530

0.338

T2. Bonus to Top

0.567

0.369

T3. Matching Bonus

0.227

0.131 
Table A2. Regression Analysis of Treatment Effects on Amount Donated by an Individual (Original and All Organizations Bonus Eligible Sessions combined)

(1) (2)

\begin{tabular}{|c|c|c|}
\hline & Total Donation ${ }^{a}$ & Total Donation $^{\mathrm{a}}$ \\
\hline All Organizations Bonus Eligible Sessions & $\begin{array}{l}-0.40 \\
(0.53)\end{array}$ & $\begin{array}{l}-0.59 \\
(0.54)\end{array}$ \\
\hline T1. Bonus Raffle & $\begin{array}{c}0.53^{* * *} \\
(0.17)\end{array}$ & $\begin{array}{c}0.51^{* * *} \\
(0.16)\end{array}$ \\
\hline T2. Bonus to Top Org. & $\begin{array}{c}0.36^{* *} \\
(0.18)\end{array}$ & $\begin{array}{c}0.35^{* *} \\
(0.18)\end{array}$ \\
\hline T3. Matching Bonus & $\begin{array}{l}0.40^{* *} \\
(0.20)\end{array}$ & $\begin{array}{r}0.39 * * \\
(0.19)\end{array}$ \\
\hline $\begin{array}{l}\text { All Organizations Bonus Eligible Sessions } \\
\text { x Bonus Raffle }\end{array}$ & $\begin{array}{c}0.25 \\
(0.32)\end{array}$ & $\begin{array}{c}0.25 \\
(0.32)\end{array}$ \\
\hline $\begin{array}{l}\text { All Organizations Bonus Eligible Sessions } \\
\text { x Bonus to Top Org. }\end{array}$ & $\begin{array}{c}0.23 \\
(0.33)\end{array}$ & $\begin{array}{c}0.23 \\
(0.33)\end{array}$ \\
\hline $\begin{array}{l}\text { All Organizations Bonus Eligible Sessions } \\
\text { x Matching Bonus }\end{array}$ & $\begin{array}{l}-0.04 \\
(0.35)\end{array}$ & $\begin{array}{l}-0.03 \\
(0.35)\end{array}$ \\
\hline Sequence $=2$ & & $\begin{array}{l}-0.12 \\
(0.13)\end{array}$ \\
\hline Sequence $=3$ & & $\begin{array}{l}-0.14 \\
(0.15)\end{array}$ \\
\hline Sequence $=4$ & & $\begin{array}{c}0.02 \\
(0.14)\end{array}$ \\
\hline Male & & $\begin{array}{l}-0.48 \\
(0.44)\end{array}$ \\
\hline Altruism & & $\begin{array}{l}0.04^{* *} \\
(0.02)\end{array}$ \\
\hline Economics Major & & $\begin{array}{l}-0.99 \\
(0.90)\end{array}$ \\
\hline Took at least 2 economics classes & & $\begin{array}{c}-0.91^{* *} \\
(0.43)\end{array}$ \\
\hline Race $=$ White & & $\begin{array}{c}0.08 \\
(0.54)\end{array}$ \\
\hline Race $=$ Asian & & $\begin{array}{c}0.40 \\
(0.56)\end{array}$ \\
\hline Under 25 years of Age & & $\begin{array}{c}0.36 \\
(0.51)\end{array}$ \\
\hline Constant & $\begin{array}{c}5.52 * * * \\
(0.28) \\
\end{array}$ & $\begin{array}{c}4.63^{* * *} \\
(1.00) \\
\end{array}$ \\
\hline $\begin{array}{l}\text { \# Observations } \\
\text { \# Unique Subjects }\end{array}$ & $\begin{array}{l}920 \\
230\end{array}$ & $\begin{array}{l}920 \\
230\end{array}$ \\
\hline$\frac{\text { Hypothesis tests ( } \mathrm{p} \text {-values for } \mathrm{H}_{0} \text { : Origina }}{\text { Within Treatment Comparisons }}$ & All Organization & Eligible Sessions) \\
\hline T0: Baseline & 0.45 & 0.28 \\
\hline T1: Bonus Raffle & 0.76 & 0.51 \\
\hline T2: Bonus to Top Org. & 0.73 & 0.49 \\
\hline T3: Matching Bonus & 0.38 & 0.23 \\
\hline Between Treatment Comparisons & & \\
\hline T0-T1: Baseline - Bonus Raffle & 0.44 & 0.43 \\
\hline T0-T2: Baseline - Bonus to Top Org. & 0.49 & 0.49 \\
\hline T0-T3: Baseline - Matching Bonus & 0.91 & 0.93 \\
\hline
\end{tabular}

\footnotetext{
${ }^{a}$ Note that since all nonprofits were eligible, total donations are identical to donations to eligible organizations.
} 
Results are based linear regression with random effects for each subject and standard errors clustered at the session level. Standard errors in parentheses. ${ }^{* * *} \mathrm{p}<0.01,{ }^{* *} \mathrm{p}<0.05,{ }^{*} \mathrm{p}<0.10$ 
Figure 1. Screen from Bonus to Top Organization

\begin{tabular}{|c|c|c|c|c|c|}
\hline \multirow{4}{*}{$\begin{array}{l}\text { Decision 1: } \$ 10.00 \\
\text { remaining } \\
\begin{array}{l}\text { Decision 2: } \$ 10.00 \\
\text { remaining }\end{array} \\
\begin{array}{l}\text { Decision 3: } \$ 10.00 \\
\text { remaining }\end{array}\end{array}$} & \multirow{2}{*}{\multicolumn{5}{|c|}{$\begin{array}{l}\text { Bonus to Top Organization } \\
\text { For today's experiment, four nonprofit organizations have been selected at random to be eligible for a top recipient bonus. An additional } \$ 100 \text { bonus } \\
\text { donation will be made to the one nonprofit (of the four that are eligible) that receives the most money donated by you and the other } 9 \text { participants. In } \\
\text { the case of a tie, the recipient of the bonus will be selected randomly. Everyone in the experiment has the same set of } 4 \text { eligible nonprofits. }\end{array}$}} \\
\hline & & & & & \\
\hline & Charity Name & Charity Description & \multicolumn{2}{|l|}{ Amount } & \multirow[t]{2}{*}{ Bonus Eligible } \\
\hline & USA for the United Nations High Commissioner for Refugees (UNHCR) & Description & $\$ 0.00$ & 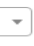 & \\
\hline \multirow[t]{8}{*}{$\begin{array}{l}\text { Decision 4: } \$ 10.00 \\
\text { remaining }\end{array}$} & Bean's Cafe & Description & $\$ 0.00$ & 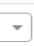 & \\
\hline & Doctors Without Borders & Description & $\$ 0.00$ & $r$ & \\
\hline & American Family Association (AFA) & Description & $\$ 0.00$ & 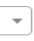 & \\
\hline & Planned Parenthood Federation of America & Description & $\$ 0.00$ & 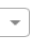 & Bonus Eligible \\
\hline & Food Bank of Alaska & Description & $\$ 0.00$ & 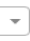 & Bonus Eligible \\
\hline & Brady Campaign to Prevent Gun Violence & Description & $\$ 0.00$ & 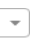 & Bonus Eligible \\
\hline & National Rifle Association Foundation & Description & $\$ 0.00$ & 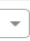 & Bonus Eligible \\
\hline & Keep for Self & & $\$ 0.00$ & 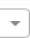 & \\
\hline
\end{tabular}

Figure 2. Distribution of the Number of Nonprofits to Which an Individual Donated (Original Sessions)
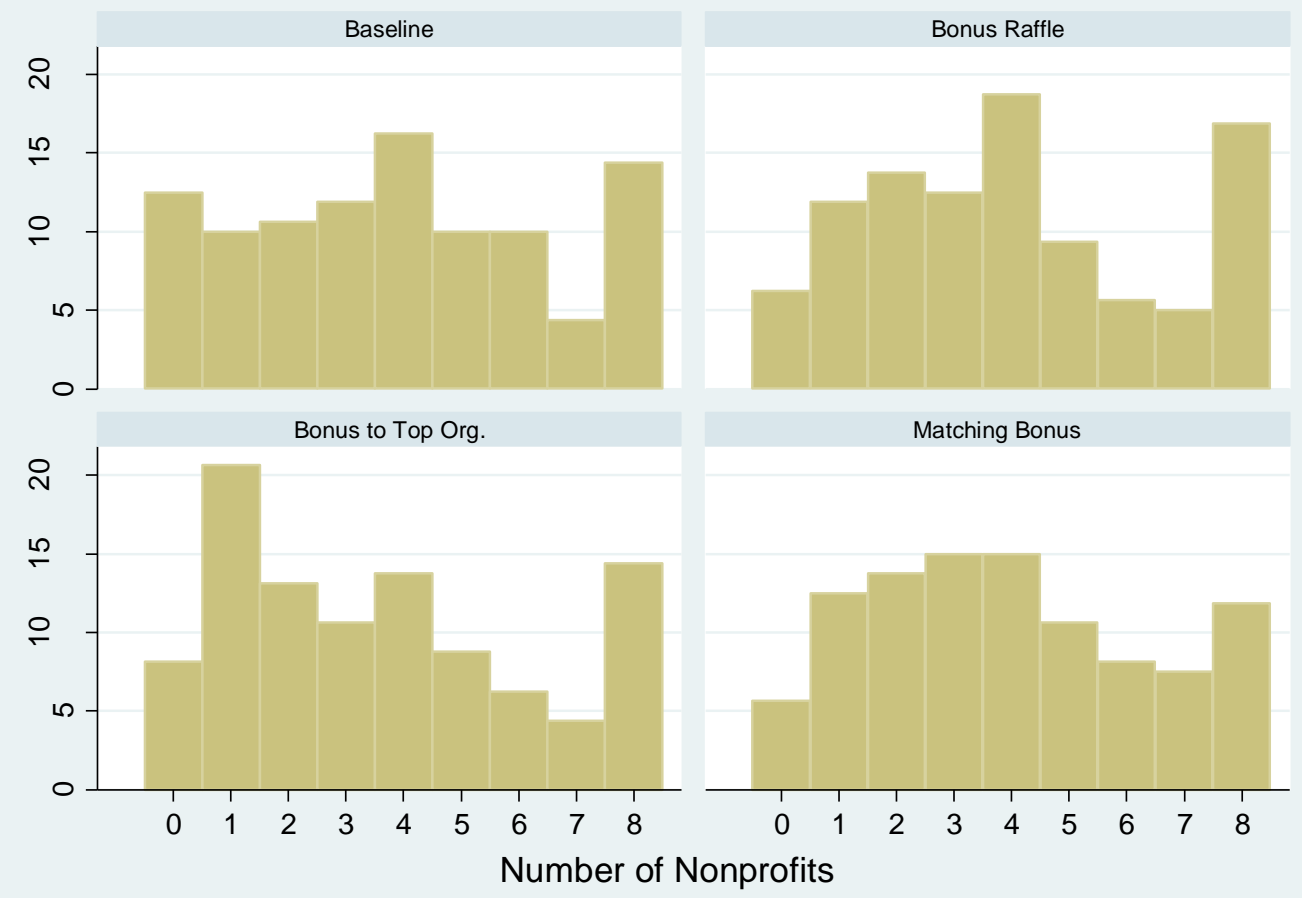

160 unique subjects 
Figure 3. Mean Donation to Each Nonprofit in the Baseline Treatment, Based on Nonprofit's Eligibility for Bonus in Other Treatments (Original Sessions)

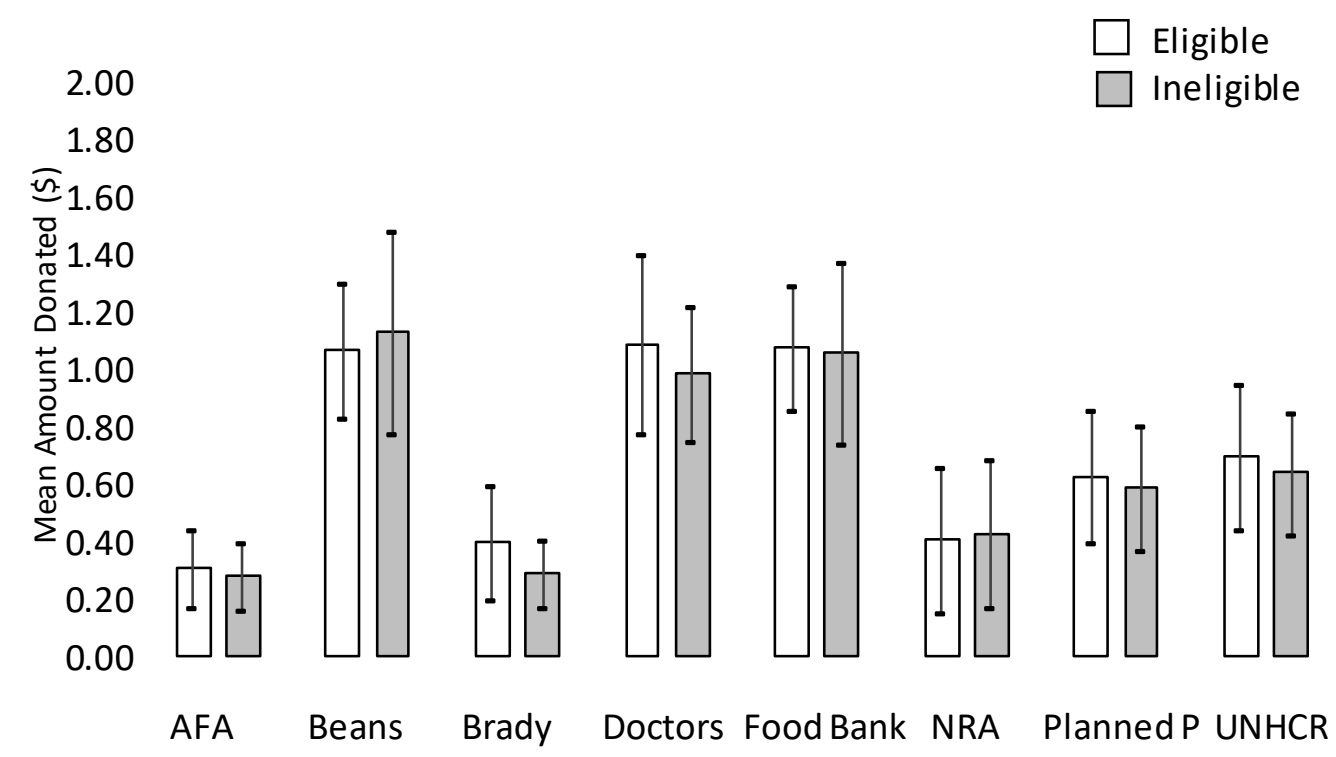

Error bars reflect $95 \%$ confidence intervals.

Figure 4. Mean Percent of Participants Who Donated to Each Nonprofit in the Baseline Treatment, Based on Nonprofit's Eligibility for Bonus in Other Treatments (Original Sessions)

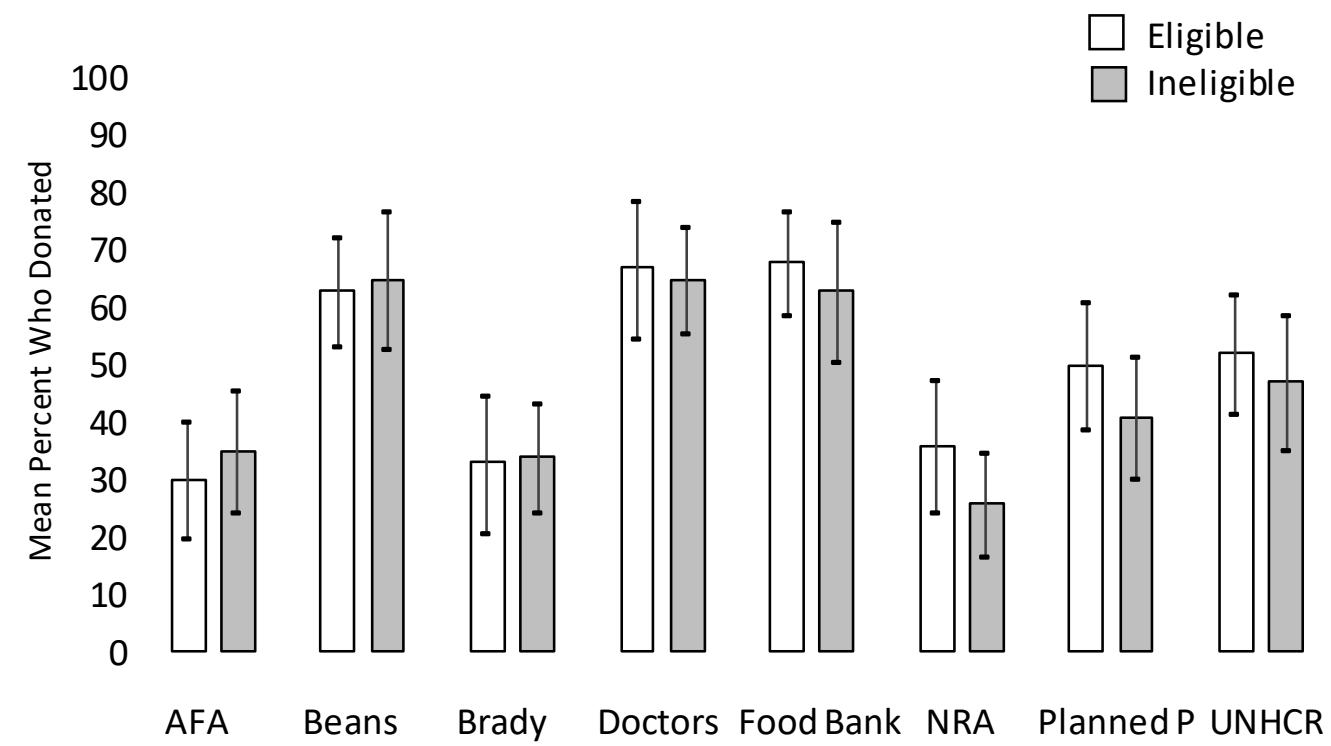

Error bars reflect $95 \%$ confidence intervals. 
Figure 5. Mean Donation to Each Nonprofit in the $\mathbf{3}$ Bonus Treatments Combined, Based on Nonprofit's Eligibility for Bonus (Original Sessions)

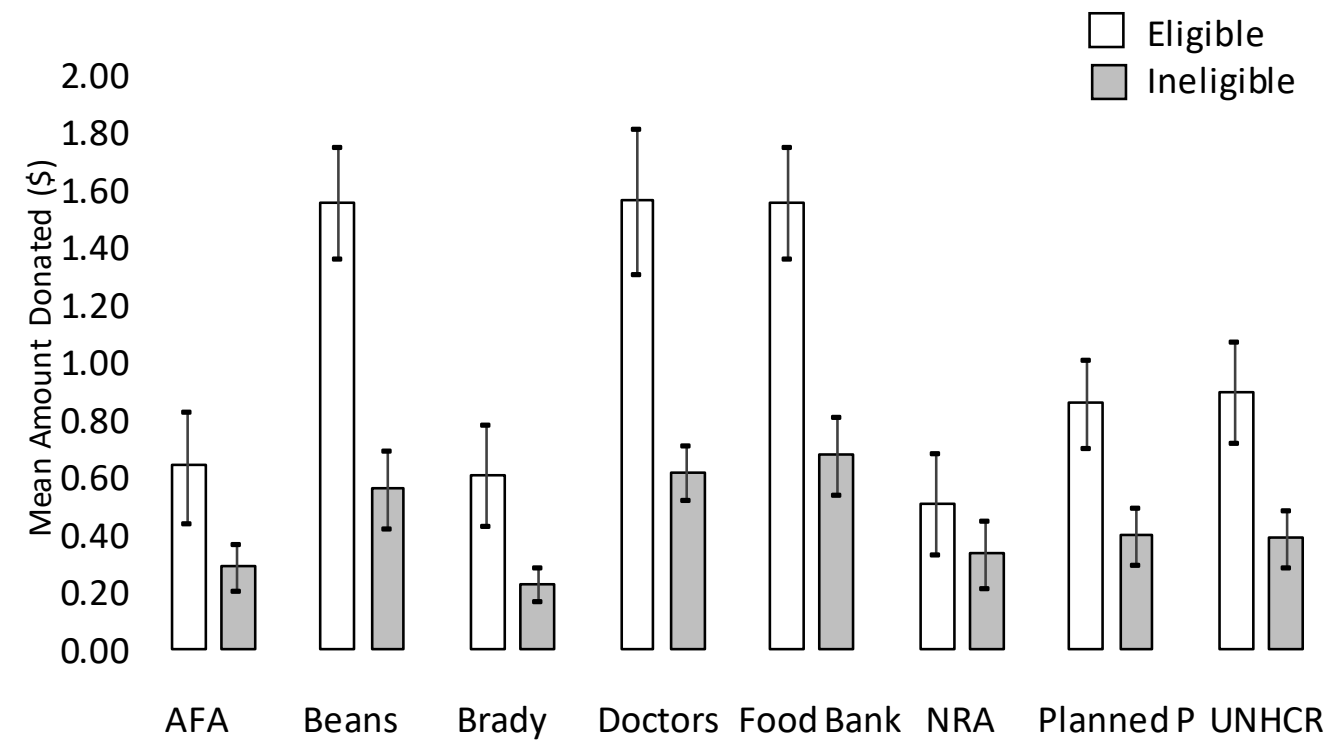

Error bars reflect $95 \%$ confidence intervals.

Figure 6. Mean Percent of Participants Who Donated to Each Nonprofit in the 3 Bonus Treatments Combined, Based on Nonprofit's Eligibility for Bonus (Original Sessions)

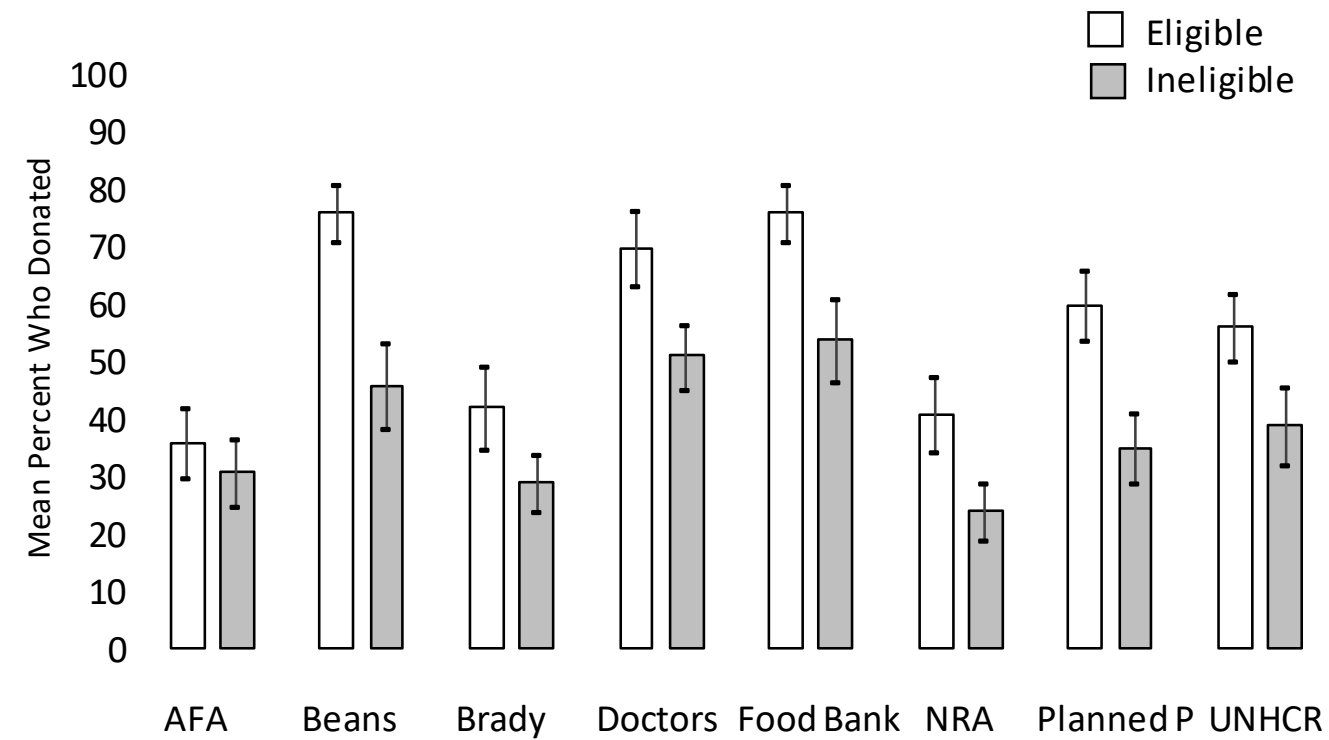

Error bars reflect $95 \%$ confidence intervals. 
Figure 7. Distribution of the Number of Nonprofits to Which an Individual Donated (All Organizations Bonus Eligible Sessions)
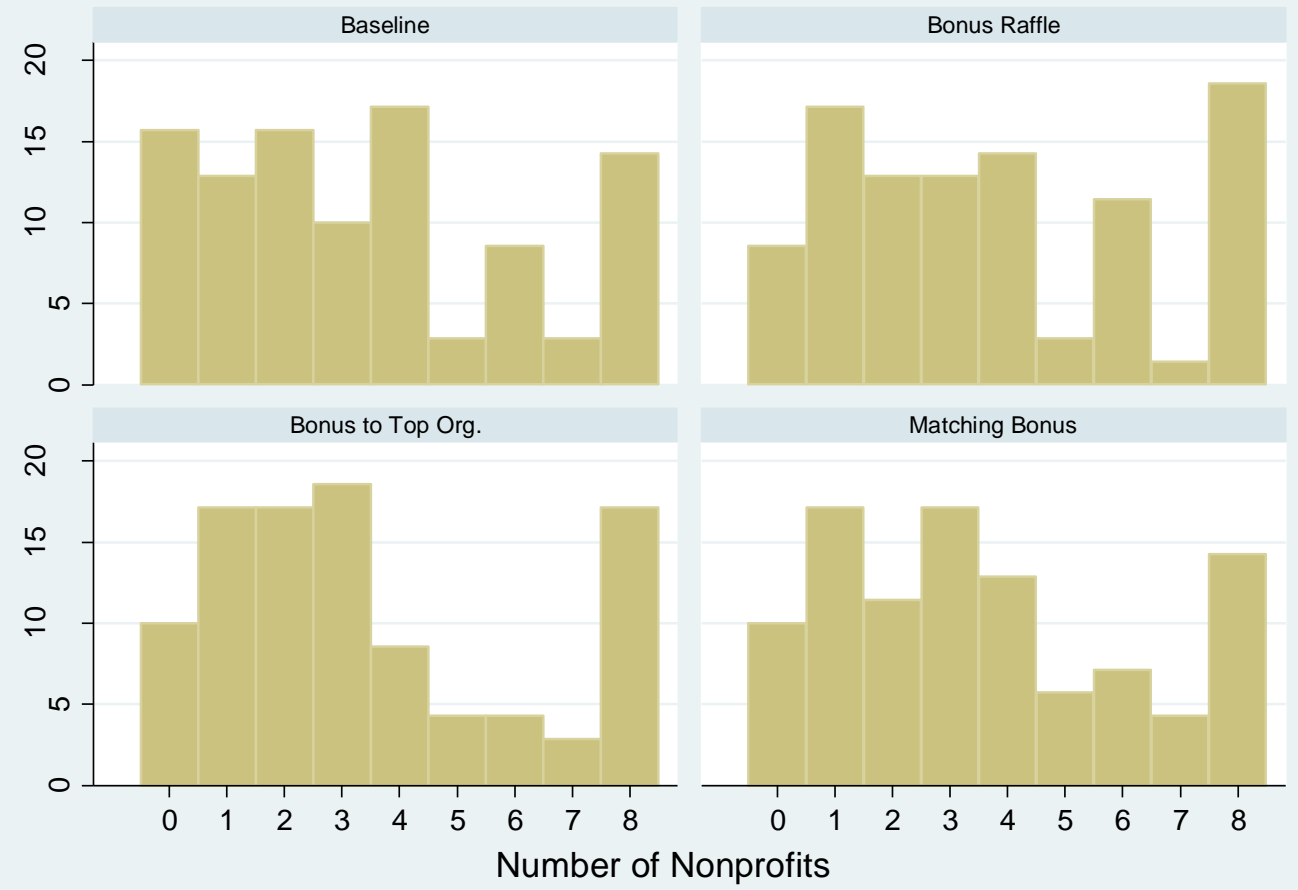

70 unique subjects 
Figure 8. Mean Donation to Each Nonprofit in the Baseline Treatment (All Organizations Bonus Eligible Sessions)

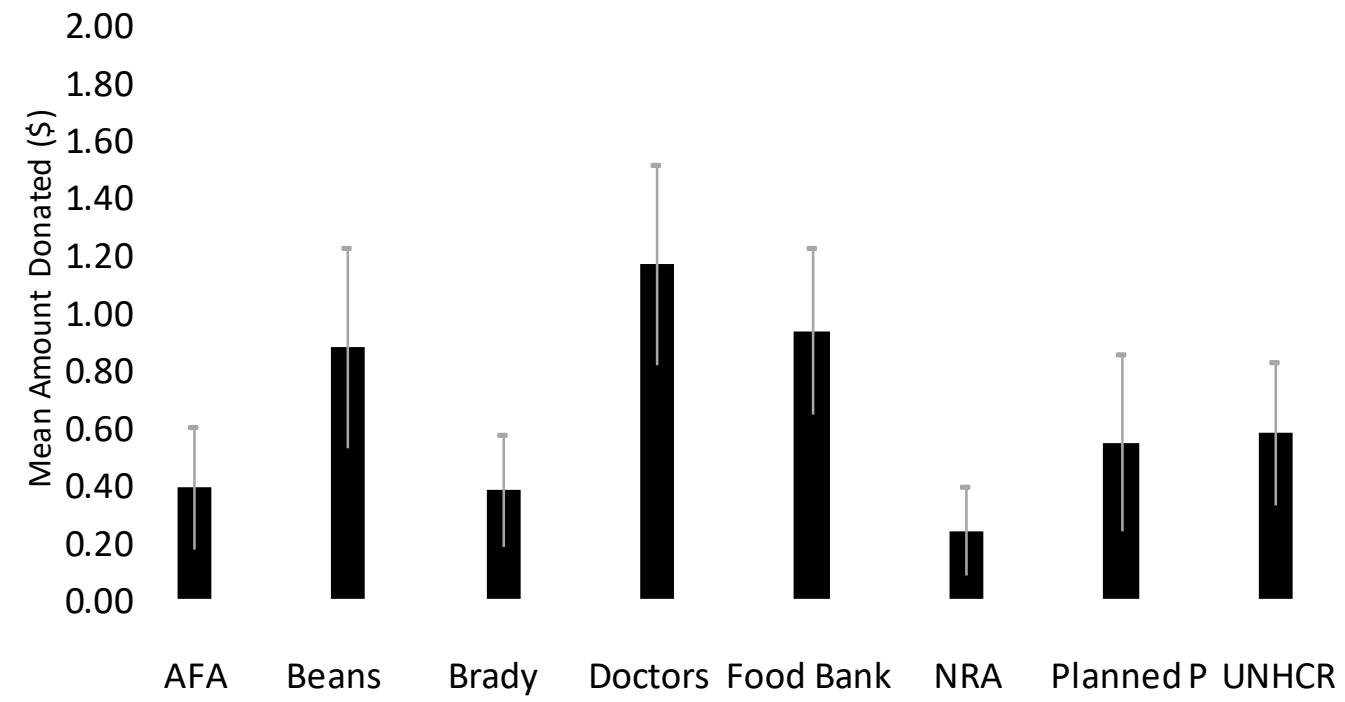

Error bars reflect $95 \%$ confidence intervals.

Figure 9. Mean Percent of Participants Who Donated to Each Nonprofit in the Baseline Treatment (All Organizations Bonus Eligible Sessions)

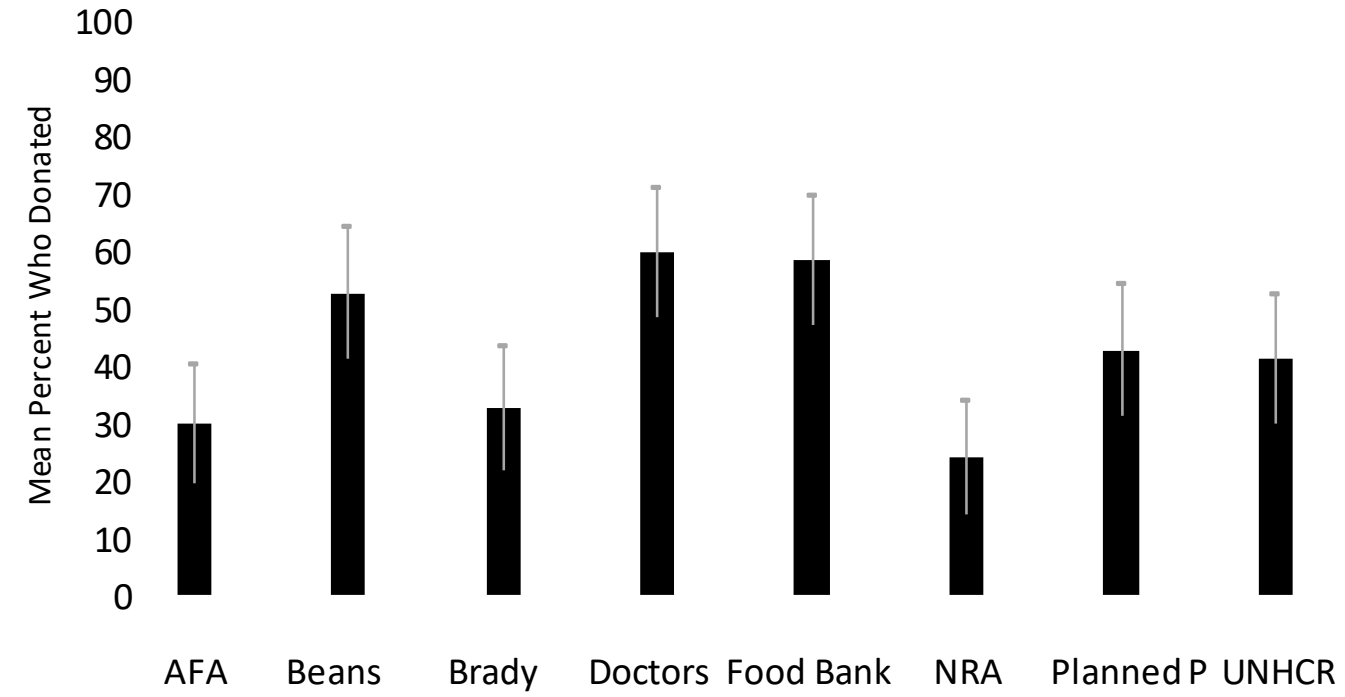

Error bars reflect $95 \%$ confidence intervals. 
Figure 10. Mean Donation to Each Nonprofit in the 3 Bonus Treatments Combined (All Organizations Bonus Eligible Sessions)

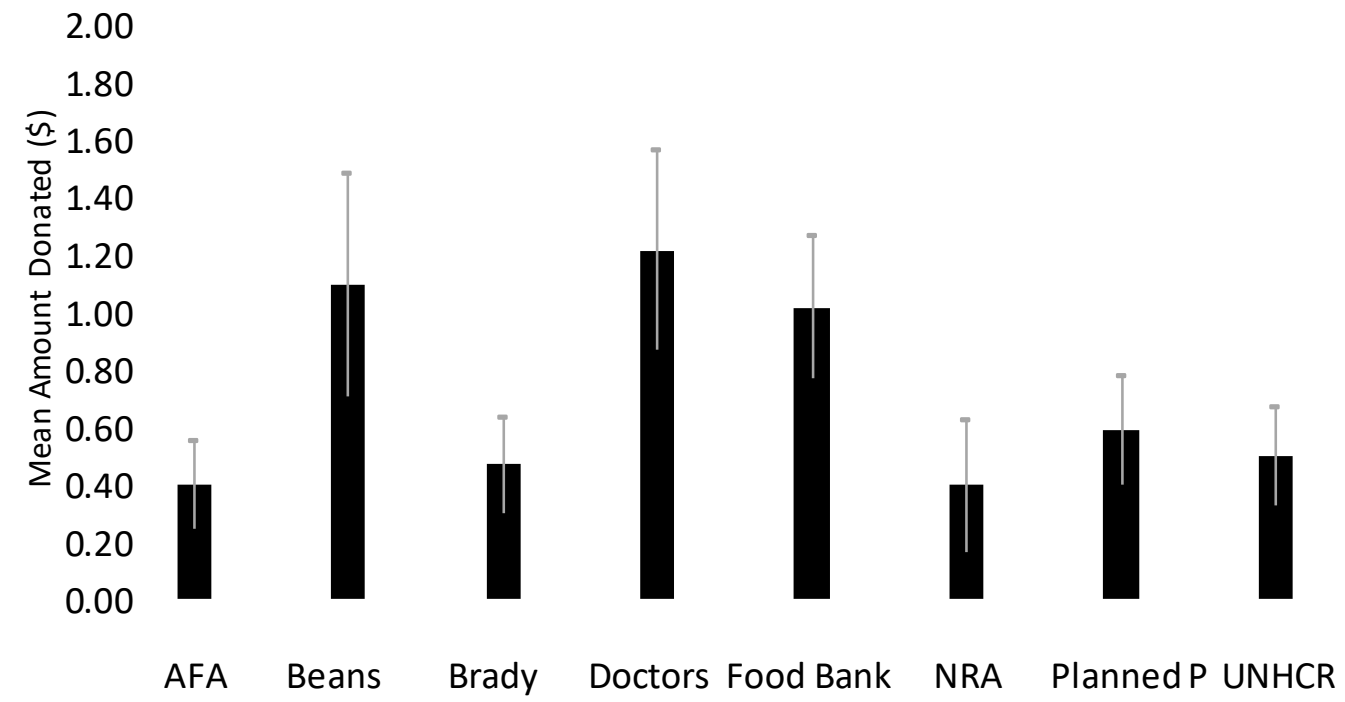

Error bars reflect $95 \%$ confidence intervals.

Figure 11. Mean Percent of Participants Who Donated to Each Nonprofit in the 3 Bonus Treatments Combined (All Organizations Bonus Eligible Sessions)

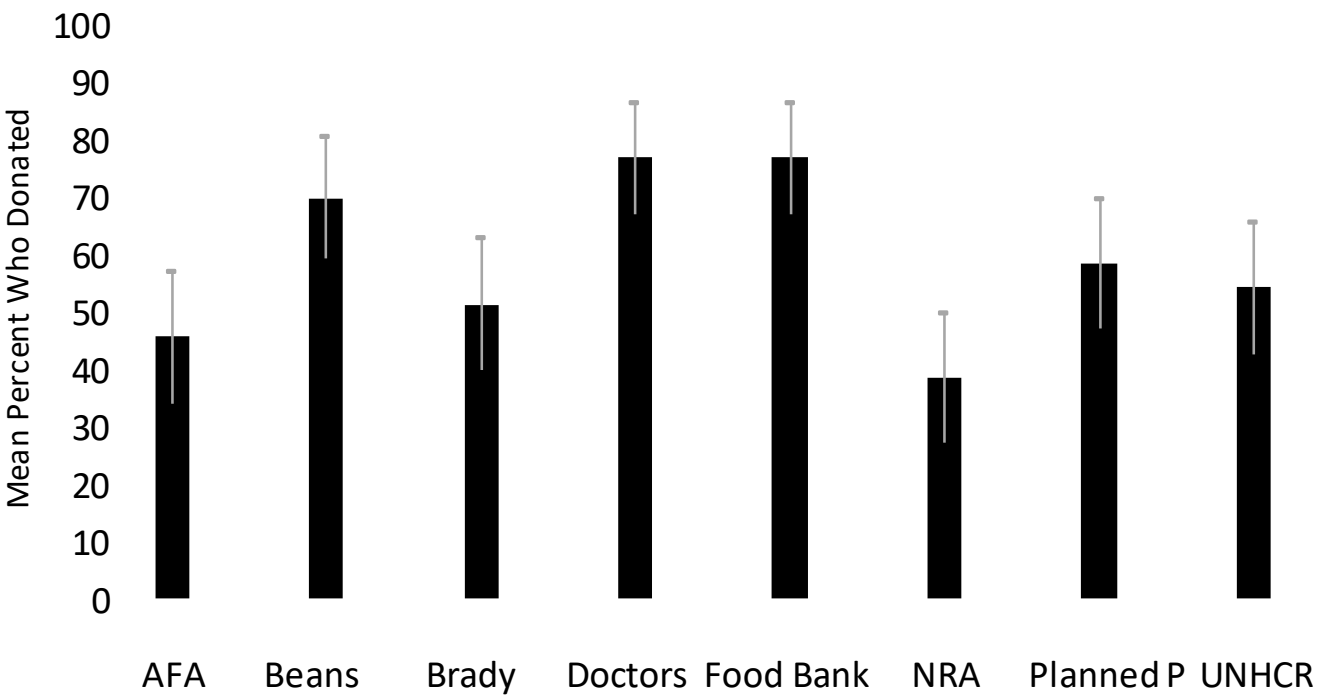

Error bars reflect $95 \%$ confidence intervals. 